Article

\title{
Board Human Capital and Enterprise Growth: A Perspective of Ambidextrous Innovation
}

\author{
Zhui Liu ${ }^{1, *}$, Guo-Dong $\mathrm{Chi}^{1}$ and Liang Han ${ }^{2}$ \\ 1 School of Economics and Management, Shihezi University, Shihezi 832000, China \\ 2 Henley Business School, University of Reading, Reading RG6 6UD, UK \\ * Correspondence: liuzhui2007@126.com; Tel.: +86-180-9758-0152
}

Received: 20 June 2019; Accepted: 19 July 2019; Published: 23 July 2019

\begin{abstract}
This paper investigates the relationship between board human capital and enterprise growth. By analysing data from Chinese publicly listed companies between 2008 and 2017, we apply resource-based theory and endogenous growth theory to develop a model, and we show board human capital has positive effects on enterprise growth and ambidextrous innovation mediates between them. We further consider the role of industry differences and market competition and show empirical evidence that board human capital has a favorable impact on enterprise growth, and such an effect is more prominent in the high-tech industry. In addition, our results suggest that ambidextrous innovation plays a partial intermediary role between board human capital and enterprise growth. Such a favorable effect is prominent in the high-tech industry but is not affected by market competition. Furthermore, the promotion of exploratory innovation is not affected by the nature of the industry, but the promotion effect is more pronounced when the market competition is weak. We finally discuss the implications of the findings for scholars, managers, and policymakers alike.
\end{abstract}

Keywords: enterprise growth; board human capital; ambidextrous innovation; industry differences; market competition

\section{Introduction}

Enterprise growth is one of the main driving forces for sustainable economic development and an important indicator for measuring the operating status and development prospects of listed enterprises [1]. Currently, China's economy is shifting from a high-speed growth to a high-quality development stage, which is composed of transforming the pattern of development, optimizing the economic structure, and transforming growth drivers. Therefore, how to transform the economic growth mode and to achieve sustainable and stable development has become one of the key issues in the process of survival and development for many enterprises. However, the factors affecting enterprise growth are too complicated. The research on the long-term mechanism of enterprises is not mature yet, and the related research on the growth of enterprises has not yet formed a unified theoretical system. As an organizational phenomenon, enterprise growth is determined by the strategic decisions made and implemented by managers when interacting with firm resources [2]. Although some scholars have proposed the theoretical research framework of "enterprise resources-enterprise capabilities-enterprise growth," it has not yet revealed in depth how the internal special resources or core competencies of enterprises play a role as the "original motive force" for enterprise growth [3]. Therefore, combined with the domestic and international situation, how to improve the core competitiveness and crack the "black box problem" of the long-term growth mechanism of enterprises is still the top priority of corporate governance research at present.

Undoubtedly, the construction of the core competence of enterprises cannot be separated from adequate resources that guarantee effective strategic decision-making. The management is the 
distributor of enterprise core resources and the decision-maker of the strategic plan, who ultimately makes, influences, and is responsible for the key resources related to new products and technology investment [4]. Agency theory suggests that once the management has self-seeking behavior, it may damage the rights and interests of shareholders and harm the sustainable development of enterprises. Hence, the corporate governance mechanism comes into being, especially the existence of the board of directors. The board of directors is the core institution of corporate governance [5], which is responsible for providing resources and consulting, in addition to acting as the shareholder trustee. Therefore, the board of directors plays an irreplaceable role in implementing management monitoring, reducing agency costs, and other aspects of corporate governance. However, the board of directors can only weaken the agency problem to a certain extent, and the degree of weakening is affected by its human capital and social capital [6]. Previous studies have been mainly based on the principal-agent theory and the resource dependence theory from the perspective of the supervision function and resource function of the board of directors, respectively [7,8]. They confirmed the importance of board capital for enterprise growth, but ignored the positive role of board capital in building the core competitiveness. According to the resource dependence theory, an effective board of directors should contain sufficient human capital and social capital, which together constitute board capital, and can measure the ability of the board to provide resources for enterprises [9]. According to the resource-based theory, heterogeneous resources owned by enterprises determine the difference in the competitiveness of enterprises, and it is believed that only valuable, rare, incompletely mimetic, and irreplaceable resources can generate sustainable competitive advantages [10]. Indeed, board capital is the heterogeneous resource of an enterprise.

Innovation is the key to building the core competitiveness of enterprises. However, enterprises are constantly faced with a dilemma in the process of pursuing innovation. From the perspective of organizational innovation capabilities, if enterprises are too keen to pursue their core competencies and cannot adapt to the rapidly changing market environment, this will easily lead to "core rigidities" and "competency traps." Similarly, if enterprises overemphasize technology research and development and neglect market demand and technological transformation, they will easily fall into the "innovation trap" [11,12]. This requires enterprises to attach importance to two kinds of innovations. On the one hand, exploitative innovation can enhance the utilization rate of existing knowledge, capabilities, and skills, and stabilize the market position and earnings by continuing the existing business model. On the other hand, exploratory innovation continuously breaks through existing technology in order to adapt to future changes in the market demand and competitive environment [13]. In other words, enterprises should pursue both exploitative innovation and exploratory innovation, namely ambidextrous innovation. In fact, whether we recognize the essence of innovation or attach importance to innovation depends largely on the level of board human capital. The existing literature has only examined the relationship between board human capital and the level of enterprise innovation. As for the relationship between board human capital and ambidextrous innovation, the literature neither elaborates the logical and rigorous theory under the normative management analysis framework nor offers rigorous and detailed empirical analysis. Therefore, it is difficult to reveal the entangled relationship between board human capital and the construction of the competitive advantage of enterprises.

In this paper, we explore the route of board human capital that influences enterprise growth, introduce ambidextrous innovation as the intermediary variable, and explore the differences in the factors affecting enterprise growth and ambidextrous innovation. We find that board human capital significantly and positively affects enterprise growth, in which ambidextrous innovation plays the part of a mediating role, and its balance effect can significantly enhance enterprise growth to a certain extent. Board human capital plays a more significant role in promoting enterprise growth in the high-tech industry, while its role in promoting ambidextrous innovation is affected by the nature of the industry and market competition. Specifically, the promotion of exploitative innovation is more significant in the high-tech industry, but not affected by market competition, and the promotion effect 
on exploratory innovation is not affected by the nature of the industry, but it is more significant when the market competition is weak. In addition, we show significant industry differences in the role of ambidextrous innovation in promoting enterprise growth. Among them, the promotion effect of exploitative innovation is more significant in non-high-tech industries, while the promotion effect of exploratory innovation is more significant in high-tech industries.

\section{The Analysis of the Mechanism of Board Human Capital Affecting Enterprise Growth}

\subsection{Board Human Capital and Enterprise Growth}

The board of directors plays a vital role in the linkage between enterprises and social resources, fulfilling its role of supervision and resource provision. Board human capital is the general term for the speciality, experience, knowledge, skills, and abilities of board members [8]. As a special resource within enterprises, human capital enhances the ability of directors to identify and utilize business opportunities or supervise and manage behaviors [14], affecting the acquisition of enterprise resources, strategic decision-making, and management operations [15]. Listed companies are increasingly favoring candidates with high academic qualifications, specific job experience, and overseas background when recruiting, and has even become a hard requirement for recruiting management, which provides an important source of indicators for the study of board human capital. Previous studies have used the board's education level, board's professional background [9], and board's overseas experience [16] to measure board human capital and studied its impact on innovation investment and corporate performance.

To a certain extent, education level reflects the knowledge reserve and professionalization of directors, and affects their thinking mode and ability for information processing, which is of great significance to corporate governance and corporate performance. The education level of directors has an important influence on the strategic preference of enterprises [16]. This is because the formulation of a corporate strategy needs a long-term awareness and overall situation consciousness. The generation of strategic thinking is restricted and influenced by the level of theory and knowledge. The more education the directors have, the more reasonable their strategic thinking is. It is more conducive to the formulation of corporate growth strategies. Furthermore, directors with a higher education level would have a stronger ability to obtain and utilize information [8]. They can objectively evaluate the risks and benefits of R\&D investment by analyzing and examining the net present value of existing projects for the enterprises. They also have a deeper understanding of the planned or current $R \& D$ investment projects and prevent the loss of opportunities or engage in excessive investment. Therefore, the higher a board's education level, the better the enterprise growth.

At present, overseas experience, such as overseas educational experience or overseas work experience, has become an important way to introduce intelligence. A board's overseas experience helps them to receive a good education and to accumulate advanced management experience, making their thinking mode and management concepts more international and market-oriented [17]. Returnee directors usually have a deeper understanding of the international market, overcome the psychological distance of overseas business expansion, make appropriate overseas business decisions [18], and improve the investment efficiency of enterprises [19]. Furthermore, the returnee directors are more capable of addressing the challenges, difficulties, and complexities associated with internationalization [20], and enable enterprises to respond more flexibly and actively to the changes in the international markets, and help to introduce advanced management experience and production technology to promote the development of overseas markets and mergers and acquisitions [21]. It is extremely important to attract excellent talent at home and abroad to promote enterprise growth. Given this evidence, we hypothesize the following:

H1. Board human capital has a favorable effect on enterprise growth.

H1a. The higher the average educational level of directors is, the better the growth of enterprises will be. 
H1b. The larger the proportion of directors with an output function background is, the more favorable it is toward improving the growth of enterprises.

H1c. The larger the proportion of directors with overseas experience is, the more conducive it is to the growth of enterprises.

\subsection{The Relationship between Board Human Capital and Ambidextrous Innovation}

Ambidextrous innovation includes exploitative innovation and exploratory innovation, among which, exploitative innovation focuses on the optimization and improvement of products, which is a small-scale and gradual innovation behavior; meanwhile, exploratory innovation focuses on seeking new possibilities, which is a large-scale and breakthrough innovation [22].

Directors with a higher education level have abundant knowledge reserves and excellent information-processing capabilities, guiding enterprises to enhance their innovation intensity to cope with the challenges of rapid changes in the external environment $[23,24]$. The existing research shows that enterprises with strong human capital can deeply explore the existing knowledge of enterprises and improve the efficiency of progressive innovation [25]. Well-educated directors have strong knowledge refining, integration, and improvement capabilities, thus providing practical and effective solutions for product optimization and improvement. In addition, they are also good at making high-level innovative decisions with professional knowledge [26] and help enterprises make creative breakthroughs. Highly educated decision-makers have strong information exploration and processing capabilities [27], and make more favorable decisions when enterprises face highly uncertain innovation decisions. Moreover, they pay more attention to research and development activities, and identify innovation opportunities to provide opportunities for enterprises.

The background of the "output function", such as marketing, product research, and design, is positively related to the choice of enterprise innovation strategy [28]. Directors with a background in "output function" have a deeper understanding of future product development, which will have a positive impact on technical performance [29]. Accumulated work experiences enable them to have a deeper understanding of the market positioning of products and customer needs, and to better perform their consulting functions. In particular, they can provide reasonable suggestions for the optimization and improvement of products, which is conducive to the improvement of the level and ability of enterprise innovation. Furthermore, directors with a background in "output function" have a more comprehensive understanding of the innovation process, such that they can predict and deal with potential uncertainties in innovation activities and reduce the risk of an enterprise innovation investment. Therefore, they are more inclined to increase the research and development investment, and promote the breakthrough development of an enterprise technology. It is beneficial for enterprises to carry out exploratory innovation activities. However, some studies have shown that higher levels of external R\&D experience of directors do not significantly affect an enterprise's technical performance [30].

A board's overseas experience is conducive to improving the level and ability of exploitative innovation and exploratory innovation of enterprises. On the one hand, returnee executives are generally in close contact with relevant overseas research institutions or enterprises [31], have the opportunity to access the advanced technical knowledge of developed countries, and apply them to the practice of Chinese enterprises. It is beneficial to promote the progress of technology and management capabilities of the industry as a whole. Furthermore, from the perspective of integrated resources and knowledge base, the external resources and knowledge brought by the management's overseas experience can help enterprises identify new opportunities, and develop new products and new markets. It is beneficial for enterprises to establish competitive advantages in emerging markets, and to promote technological innovation [32]. These arguments point to the following hypotheses:

H2. Board human capital promotes exploitative innovation. 
H2a. The average educational level of directors has a favorable effect on exploitative innovation.

H2b. The proportion of directors with an output function background has a favorable effect on exploitative innovation.

H2c. The proportion of directors with overseas experience has a favorable effect on exploitative innovation.

H3. Board human capital promotes exploratory innovation.

H3a. The average educational level of directors has a favorable effect on exploratory innovation.

H3b. The proportion of directors with output function background has a favorable effect on exploratory innovation.

H3c. The proportion of directors with overseas experience has a favorable effect on exploratory innovation.

\subsection{The Relationship between Ambidextrous Innovation and Enterprise Growth}

Exploitative innovation and exploratory innovation can improve enterprise growth in different ways. Enterprises are faced with the pressure of insufficient utilization of resources and "iterative optimization" in the process of growth. Exploitative innovation can improve and optimize the existing technical ability through the extraction and integration of existing knowledge [33,34], and can continuously improve the utilization and conversion rate of enterprise resources. Furthermore, it can meet the refined requirements of the products by improving and optimizing all aspects of the production, sales, and operation of enterprises, and provide better service and more abundant value transmission for the market demanders [35], so as to stabilize the current revenue and strengthen the market position of products [36]. Furthermore, enterprises are faced with insufficient core competitiveness and industry competition pressure in the process of growth. Exploratory innovation can capture the industry's right to speak by acquiring and creating new knowledge and technology [34]. It breaks through the constraints of corporate development, and helps to develop innovative products or services, effectively improving the core competitiveness of enterprises [37]. It constantly weakens the competitive pressure of the industry, and ultimately creates the overall technological breakthrough and linkage development of the industry, bringing excess profits to the enterprise [36]. Therefore, exploitative innovation and exploratory innovation have a positive significance in improving the short-term financial performance and in building the sustainable competitive advantage of enterprises. Given this evidence, we hypothesize the following:

H4a. Exploitative innovation promotes enterprise growth.

H4b. Exploratory innovation promotes enterprise growth.

The existing research suggests that the ambidextrous innovation theory should include the balance dimension and the complementary dimension, which are used to measure the balance and complementarity of exploitative innovation and exploratory innovation, respectively. Balance means that enterprises can maintain a balanced development of two kinds of innovation activities, and do not rely too much on a particular type of innovation. Complementarity refers to the fact that two kinds of innovation activities in an enterprise can promote and complement each other [38]. Specifically, balance between them can help enterprises reduce the risk of "core rigidity" or the "innovation trap" generated by one party, reduce the business risk of enterprises, and consider the short-term economic benefits and future economic growth of enterprises. When both of them are strong, the complementarity between them will appear, and their multiplier effect can significantly improve the enterprise's performance [35]. This is because when an enterprise has a strong level of, and capability for, exploitative innovation, it can deepen the application and understanding of exploratory innovation knowledge and technology so as to constantly improve and optimize the output of exploratory innovation. Similarly, when an enterprise has a strong level and ability of exploratory innovation, it can break through the problem of "iterative optimization" in the later stage of exploitative innovation and consolidate the competitive position in 
the market by realizing the breakthrough development of products or technologies. It can be seen that both exploitative innovation and exploratory innovation can coexist in an enterprise, and when their absolute value is smaller (more balanced) and the product is larger (the more complementary), the promotion of enterprise performance is more significant [39]. Given this evidence, we hypothesize the following:

H5a. The balance effect between exploitative innovation and exploratory innovation promotes enterprise growth.

H5b. The product effect of exploitative innovation and exploratory innovation promotes enterprise growth.

\subsection{The Mediating Effect of Ambidextrous Innovation}

The theory of the endogenous growth of enterprises suggests that the driving force for enterprise growth lies in the internal environment of enterprises. The internal resources, technologies, and structures of enterprises are indispensable key elements for enterprise growth. Enterprises can actively adjust these elements to improve their growth capacity. The higher a board's education level is, the stronger their understanding and application ability of knowledge will be. In addition to enhancing the knowledge reserve of enterprises, directors can provide more professional schemes for enterprises to implement product optimization, and to improve the exploitative innovation level and ability of enterprises. Meanwhile, directors are exposed to the latest discoveries or cutting-edge research in their areas when they receive a higher education level. They often break through the existing knowledge and technology limitations in the industry and provide opportunities for enterprises to implement exploratory innovation. Directors with a background in "output function" have been in the forefront of production and sales for a long time, and their long-term accumulated experiences enable them to have a clearer understanding of the product market and customer demand. It is usually the basis and key point for enterprises to carry out exploitative innovation. In addition, directors with a background in "output function" pay more attention to the research and development investment of enterprises. At the same time, they are the main promoters of the technological revolution, and effectively remove various obstacles in technological change and achieve a successful transformation. Therefore, directors with this background can significantly improve the level and ability of exploratory innovation. A board's overseas experience can introduce foreign advanced technology and knowledge into enterprises, improve the technology and ability of enterprises as a whole, and promote the exploitative innovation of enterprises to achieve long-term development. Furthermore, it is helpful for enterprises to deepen their understanding of independent innovation [18], and identify new opportunities, which is of great significance for achieving technological breakthroughs and developing emerging markets, thus greatly improving the exploratory innovation level and capabilities of enterprises.

In summary, board human capital can improve the level and ability of an enterprise's ambidextrous innovation in two ways. First, it can use the existing knowledge, skills, and abilities to gradually improve the products and technologies of enterprises, and improve the level and ability of exploitative innovation of enterprises. Second, the breakthrough development of new products and technologies of enterprises can be realized by tackling key problems regarding new knowledge and technologies. Further, exploitative innovation can make full use of enterprise resources, realize iterative optimization of enterprise technology and products, and promote the improvement of the short-term financial performance of enterprises [40]. Exploratory innovation can solve the problem of insufficient core competitiveness of enterprises, alleviate the competitive pressure of enterprises, and have far-reaching significance toward building the core competitive advantages of enterprises. It can be seen that ambidextrous innovation has profoundly affected the improvement of short-term performance and the construction of long-term sustainable competitive advantage [41]. Therefore, board human capital can promote enterprise growth by influencing ambidextrous innovation; that is, ambidextrous innovation has an intermediary effect between board human capital and enterprise growth. Therefore, we hypothesize the following: 
H6. Exploitative innovation and exploratory innovation mediate between board human capital and enterprise growth.

H6a. Exploitative innovation and exploratory innovation mediate between a board's education level and enterprise growth.

H6b. Exploitative innovation and exploratory innovation mediate between a board's professional background and enterprise growth.

H6c. Exploitative innovation and exploratory innovation mediate between a board's overseas experience and enterprise growth.

The theoretical model of this study is shown in Figure 1.

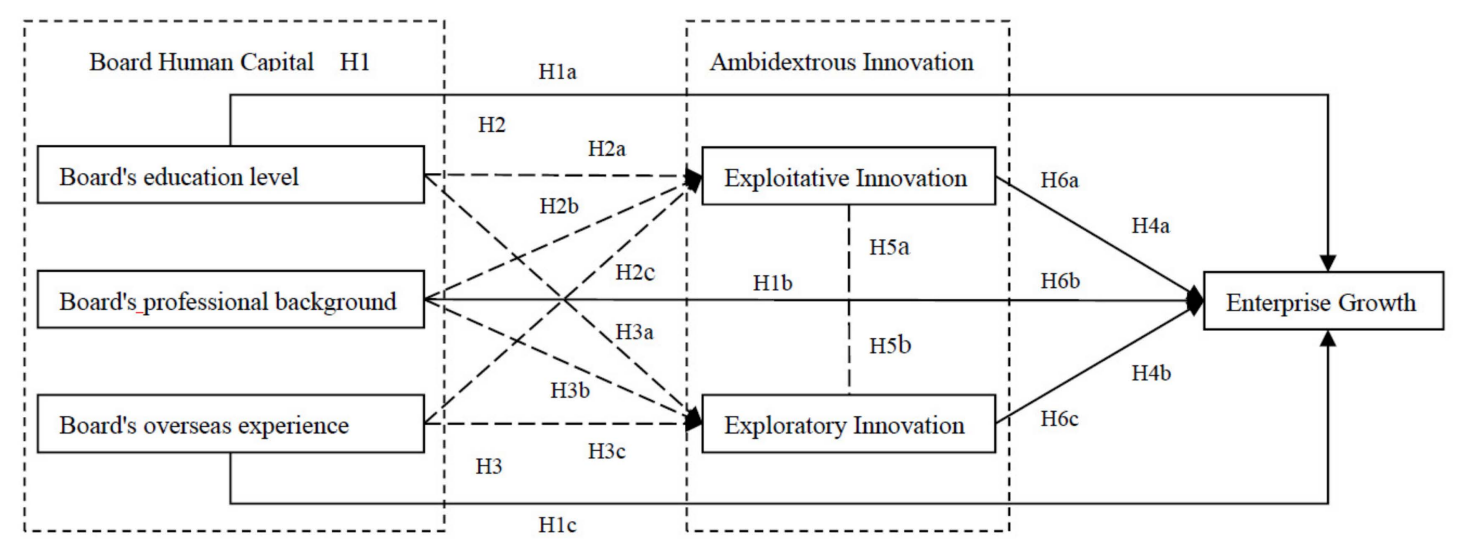

Figure 1. Theoretical Model.

\section{Data Sources and Research Design}

\subsection{Sample Selection and Data Sources}

We select Chinese A-share non-financial listed companies from 2008 to 2017 as the research sample, which specifically includes both of the A-share Main Board and SME Board listed companies of the Shanghai and Shenzhen Stock Exchange in China, except financial and insurance firms. The reasons are as follows: First, the relevant field information on the board of directors disclosed by CSMAR (China Stock Market \& Accounting Research) mainly started in 2008, and the 10-year data are selected to ensure the validity of the regression results. Second, due to the large differences in accounting standards between the financial and insurance industries and other industries, the relevant indicators of the two industries are not comparable and they are eliminated. Third, the board structure of listed companies on the Main Board and SME Board has improved, and the corporate governance mechanism is reasonable, which is conducive to playing the role of board human capital. Fourth, considering that a board's overseas experience is an important part of board human capital, due to the high internationalization level of listed companies on the Main Board and SME Board, the proportion of directors with overseas experience is relatively high. In contrast, gem enterprises are small in scale, with imperfect board governance structures and high risks, and as such, they are not included in the sample scope.

In addition, we followed existing literature by removing ST (Special Treatment) and PT (Particular Transfer) listed company samples, and deleting samples with abnormal financial data and serious missing data. After screening, we finally obtained 17,357 initial samples. In order to prevent the extreme value, all continuous variables were subjected to a $1 / 99 \%$ winsorization. The statistical analysis software used was Stata14.0 (Source Location: Shihezi University, Shihezi, Xinjiang, China). 


\subsection{Indicator Selection and Variable Definition}

Dependent Variables: Enterprise Growth. Considering the cumulative effect of board human capital, Tobin's $Q$, which reflects the ability of enterprise development, was used as the proxy variable for enterprise growth in accordance with the research of Wang et al. [42]. In the robustness test, we followed Fang et al. [43] and took the growth rate of the enterprise operating income as an alternative indicator of growth.

Independent Variables: Board Human Capital (BHC). The board human capital was measured by three variables: board's education level (DEI), board's professional background (BAC), and board's overseas experience (SEA). Among them, a board's education level was calculated by taking the average of the highest education degree of directors, and organizing the education degree of directors from the lowest to the highest. The education level below the undergraduate degree was coded as 1,2 for an undergraduate degree, 3 for a postgraduate degree, and 4 for a doctoral degree. A board's professional background was measured by the proportion of the number of directors with the background of "output functions", such as R\&D, marketing, and design, in the total number of the board of directors [44]. A board's overseas experience was measured using the proportion of directors with overseas experience to the total number of board members [16]. Drawing on the research of Wang et al. [45], board human capital was measured by standardizing and summing the board's education level, board's professional background, and board's overseas experience.

Intermediary Variables: Ambidextrous Innovation. Ambidextrous innovation was specifically divided into two methods: exploitative innovation (IOTTOU) and exploratory innovation (IOTTOE). We used the method of Bi et al. [46] for reference to measure each of them. Exploitative innovation (IOTTOU) was measured using the ratio of capitalized R\&D expenditures to total assets at the beginning of the year; and exploratory innovation (IOTTOE) was measured using the ratio of expensed R\&D expenditures to total assets at the beginning of the year.

Control Variables: In order to exclude the influence of other potential variables, the variables such as corporate characteristics and environmental characteristics are controlled by referring to relevant studies [43]. At the level of corporate characteristics, we control for enterprise size (SIZE), financial leverage ( $L E V)$, year of establishment $(A G E)$, nature of ownership (STA), ownership concentration (SEC), and combined title of board chair and CEO (DOUL). At the level of environmental characteristics, we have controlled for macroeconomic growth rate $(G D P)$. In addition, we use the dummy variables of annual (Year) and industry (IND) to control for the year and industry of the samples (see Table 1).

Table 1. Definition of variables.

\begin{tabular}{|c|c|c|}
\hline Variable Name & Symbol & Definition and Measurement \\
\hline Enterprise Growth & Growth & $\begin{array}{c}\text { Tobin's Q (value of outstanding shares + value of } \\
\text { non-tradable shares + book value of liabilities)/total } \\
\text { assets }\end{array}$ \\
\hline Board's Education Level & $D E I$ & $\begin{array}{l}\text { Measured by the average number of the highest } \\
\text { academic qualifications of the board of directors, where } \\
\text { below an undergraduate degree is worth } 1 \text {, the } \\
\text { undergraduate degree is worth } 2 \text {, a postgraduate degree } \\
\text { is worth 3, and a doctoral degree is worth } 4\end{array}$ \\
\hline $\begin{array}{l}\text { Board's Professional } \\
\text { Background }\end{array}$ & $B A C$ & $\begin{array}{l}\text { The proportion of directors with an "output function" } \\
\text { background to the total number of board members }\end{array}$ \\
\hline Board's Overseas Experience & SEA & $\begin{array}{l}\text { The proportion of directors who have overseas } \\
\text { experience }\end{array}$ \\
\hline Board Human Capital & $B H C$ & $\begin{array}{l}\text { Board human capital is a composite indicator that is } \\
\text { standardized and then is found by summing up a } \\
\text { board's education level, professional background, and } \\
\text { overseas experience }\end{array}$ \\
\hline
\end{tabular}


Table 1. Cont.

\begin{tabular}{ccc}
\hline Variable Name & Symbol & Definition and Measurement \\
\hline Exploitative Innovation & IOTTOU & $\begin{array}{c}\text { (Capitalized R\&D expenditures divided by total assets at } \\
\text { the beginning of the year) } \times 100 \%\end{array}$ \\
\hline Exploratory Innovation & IOTTOE & $\begin{array}{c}\text { (Expensed R\&D expenditures divided by total assets at } \\
\text { the beginning of the year) } \times 100 \%\end{array}$ \\
\hline Enterprise Size & SIZE & ln (enterprise ending asset +1$)$ \\
\hline Financial Leverage & LEV & $\begin{array}{c}\text { Asset-liability ratio = total liabilities divided by total } \\
\text { assets }\end{array}$ \\
\hline Year of Establishment & AGE & ln (sample year minus year of establishment) \\
\hline $\begin{array}{c}\text { Nature of Ownership } \\
\text { Ownership Concentration }\end{array}$ & STA & $\begin{array}{c}\text { If it belongs to a state-owned enterprise, set to 1; } \\
\text { otherwise, set to 0; dummy variable }\end{array}$ \\
\hline $\begin{array}{c}\text { Macroeconomic Growth Rate } \\
\text { Combined Title of Board } \\
\text { Chair and CEO }\end{array}$ & GDP & $\begin{array}{c}\text { Square sum of shareholding ratio of the top ten } \\
\text { shareholders }\end{array}$ \\
\hline Year & GOUL & $\begin{array}{c}\text { If the chairman and the general manager take a part-time } \\
\text { job, set to 1; otherwise, set to 0; dummy variable }\end{array}$ \\
\hline Industry & IND & Year1-Year10, dummy variable \\
\hline
\end{tabular}

\subsection{Model Setting}

Based on the research hypothesis, the following models were set up to be tested, where $\alpha$ is the intercept, $\beta_{\gamma}(\gamma=1, \ldots, 13)$ are the coefficients, and $\varepsilon$ is the random error term.

Model 1 validates the relationship between board human capital and enterprise growth. Therefore, a regression model with board human capital as the independent variable was established to test hypothesis $\mathrm{H} 1$ :

$$
\begin{gathered}
\text { Growth }=\alpha+\beta_{1,1} B H C\left(\beta_{1,2} D E I+\beta_{1,3} B A C+\beta_{1,4} S E A\right)+\beta_{1,5} S I Z E+\beta_{1,6} L E V \\
+\beta_{1,7} A G E+\beta_{1,8} S T A+\beta_{1,9} S E C+\beta_{1,10} G D P+\beta_{1,11} D O U L \\
+\sum Y \text { ear }+\sum I N D+\varepsilon
\end{gathered}
$$

Model 2 validates the relationship between board human capital and ambidextrous innovation, which was used to test hypotheses $\mathrm{H} 2$ and $\mathrm{H} 3$ :

$$
\begin{gathered}
\operatorname{IOTTOU}(\text { IOTTOE })=\alpha+\beta_{2,1} B H C\left(\beta_{2,2} D E I+\beta_{2,3} B A C+\beta_{2,4} S E A\right)+\beta_{2,5} S I Z E+\beta_{2,6} L E V \\
+\beta_{2,7} A G E+\beta_{2,8} S T A+\beta_{2,9} S E C+\beta_{2,10} G D P \\
+\beta_{2,11} D O U L+\sum \text { Year }+\sum I N D+\varepsilon
\end{gathered}
$$

Model 3 validates the relationship between ambidextrous innovation and enterprise growth, which was used to test hypotheses $\mathrm{H} 4 \mathrm{a}$ and $\mathrm{H} 4 \mathrm{~b}$ :

$$
\begin{aligned}
\text { Growth }=\alpha+\beta_{3,1} \text { IOTTOU } & (\text { IOTTOE })+\beta_{3,2} \text { SIZE }+\beta_{3,3} L E V+\beta_{3,4} A G E \\
+\beta_{3,5} \text { STA } & +\beta_{3,6} \text { SEC }+\beta_{3,7} \text { GDP }+\beta_{3,8} D O U L \\
& +\sum \text { Year }+\sum I N D+\varepsilon
\end{aligned}
$$


Model 4 validates the relationship between ambidextrous innovation matching patterns and enterprise growth, which was used to test hypotheses H5a and H5b:

$$
\begin{gathered}
\text { Growth }=\alpha+\beta_{4,1} \text { IOTTOU } \times \text { IOTTOE }(|\mathrm{IOTTOU}-\mathrm{IOTTOE}|)+\beta_{4,2} \mathrm{SIZE} \\
+\beta_{4,3} L E V+\beta_{4,4} A G E+\beta_{4,5} \mathrm{STA}+\beta_{4,6} \mathrm{SEC}+\beta_{4,7} \mathrm{GDP}+\beta_{4,8} D O U L \\
+\sum Y e a r+\sum \mathrm{IND}+\varepsilon
\end{gathered}
$$

Model 5 validates the mediating effect of ambidextrous innovation, which was used to test hypothesis H6:

$$
\begin{gathered}
\text { Growth }=\alpha+\beta_{5,1} B H C\left(\beta_{5,2} D E I+\beta_{5,3} B A C+\beta_{5,4} S E A\right)+\beta_{5,5} \text { IOTTOU }(\text { IOTTOE }) \\
+\beta_{5,6} \text { SIZE }+\beta_{5,7} L E V+\beta_{5,8} A G E+\beta_{5,9} S T A+\beta_{5,10} S E C+\beta_{5,11} \text { GDP } \\
+\beta_{5,12} D O U L+\sum \text { Year }+\sum I N D+\varepsilon
\end{gathered}
$$

\section{The Empirical Results and Analysis}

\subsection{Variable Description}

The results of the variable description are shown in Table 2, where Panel A reports descriptive statistics and Panel B reports the results of mean-difference tests. Panel A shows that: (1) The standard deviation of the variable Growth was up to 1.8696, indicating that there was a certain difference in the growth of the sample enterprises. (2) The coefficient of variation of the variable BHC was $243.71 \%$, indicating that the sample had strong volatility. This was because the standard deviation of the variable $B H C$ was large but its mean value was small, which indicated that the board of directors of the listed companies in China had highly different levels of human capital. However, due to the level of human capital being generally low, once listed companies raise the level of board human capital through various methods, such as recruitment of talents and organization of training, they will make significant differences relative to most listed companies, which causes the high volatility of board human capital. (3) The mean value of the variable DEI was greater than 2.5 (a postgraduate degree was worth 3), and the coefficient of variation was $20.34 \%$, indicating that a board's education level of Chinese listed companies was relatively concentrated, and the average education level was close to a graduate degree. (4) The mean value of $B A C$ was 0.2742 , which indicated that about one-third of the directors in the sample enterprises had experience in $R \& D$, design, or marketing. (5) The standard deviation of the variable SEA was 0.1129 , but the coefficient of variation was $124.2 \%$, indicating that the sample was highly volatile. This was caused by the small mean value of the variable $S E A$, which indicates that the overseas experience of directors of Chinese-listed companies is relatively concentrated. However, due to its low average proportion, once a company had a large number of returnees, it was significantly different from most companies and its volatility was greater. (6) The coefficient of variation of the variable IOTTOU was $233.15 \%$, which was much larger than the coefficient of variation of the variable IOTTOE, which was $110.77 \%$. That is to say, although the standard deviation of the variable IOTTOE was large, the variable IOTTOU had a large variability with respect to its mean value, indicating that there were some differences in the level of exploitative innovation of listed companies in China compared with exploratory innovation, the average level of exploitative innovation R\&D investment was low, and enterprises were more likely to catch up with innovation by increasing the investment; as such, the volatility of exploitative innovation was higher. (7) The standard deviation of the variable SIZE was 1.2852 , but its coefficient of variation was only 0.0582 , which was related to the large mean value of the variable SIZE. This indicates that there were large differences in the size of sample companies, and due to the generally high average size of enterprises, it was difficult for smaller enterprises to expand their size in a short time; as such, their volatility was relatively small. Panel B divides the samples into two groups according to the average value of board human capital, and tests the differences between them. The mean-difference test results show that the 
higher the level of board human capital is, the greater the enterprise growth was, consistent with the hypotheses developed earlier.

Table 2. Variable description.

\begin{tabular}{|c|c|c|c|c|c|c|c|}
\hline \multicolumn{8}{|c|}{ Panel A: Descriptive Statistics of Variables } \\
\hline $\begin{array}{l}\text { Variable } \\
\text { Name }\end{array}$ & Observations & Mean & Min & P50 & Max & SD & $\mathrm{CV}$ \\
\hline Growth & 17,357 & 2.1122 & 0.2038 & 1.5636 & 10.6556 & 1.8696 & 0.8851 \\
\hline$B H C$ & 17,357 & 0.8116 & -3.3133 & 0.6470 & 6.1729 & 1.9780 & 2.4371 \\
\hline$D E I$ & 17,357 & 2.5456 & 1.0000 & 2.6000 & 3.7500 & 0.5178 & 0.2034 \\
\hline$B A C$ & 17,357 & 0.2742 & 0.0000 & 0.2500 & 0.7778 & 0.1907 & 0.6954 \\
\hline SEA & 17,357 & 0.0909 & 0.0000 & 0.0714 & 0.5000 & 0.1129 & 1.2420 \\
\hline IOTTOU & 5796 & 0.3348 & 0.0000 & 0.0000 & 4.7003 & 0.7806 & 2.3315 \\
\hline IOTTOE & 2823 & 1.5479 & 0.0014 & 1.0902 & 9.5567 & 1.7146 & 1.1077 \\
\hline SIZE & 17,357 & 22.0724 & 19.5809 & 21.9008 & 25.9794 & 1.2852 & 0.0582 \\
\hline DOUL & 17,357 & 0.2273 & 0.0000 & 0.0000 & 1.0000 & 0.4191 & 1.8438 \\
\hline SEC & 17,357 & 0.1657 & 0.0143 & 0.1353 & 0.5717 & 0.1178 & 0.7109 \\
\hline$L E V$ & 17,357 & 0.4434 & 0.0486 & 0.4419 & 0.8883 & 0.2103 & 0.4742 \\
\hline$A G E$ & 17,357 & 2.6968 & 1.3863 & 2.7726 & 3.3673 & 0.3914 & 0.1451 \\
\hline STA & 17,357 & 0.4431 & 0.0000 & 0.0000 & 1.0000 & 0.4968 & 1.1212 \\
\hline GDP & 17,357 & 0.1138 & -0.2240 & 0.1037 & 0.3227 & 0.0554 & 0.4868 \\
\hline \multicolumn{8}{|c|}{ Panel B: Molecular Variable Difference Test } \\
\hline \multirow{2}{*}{$\begin{array}{l}\text { Explained } \\
\text { Variable }\end{array}$} & \multirow{2}{*}{$\begin{array}{l}\text { Explanatory } \\
\text { Variables }\end{array}$} & \multicolumn{2}{|c|}{ Sample Size } & \multicolumn{2}{|c|}{ Mean } & \multirow{2}{*}{\multicolumn{2}{|c|}{ Mean Difference }} \\
\hline & & High & Low & High & Low & & \\
\hline Growth & $B H C$ & 8681 & 8676 & 2.292 & 1.932 & \multicolumn{2}{|c|}{$0.360 * * *$} \\
\hline Growth & $D E I$ & 8427 & 8930 & 2.168 & 2.060 & \multicolumn{2}{|c|}{$0.108^{* * *}$} \\
\hline Growth & $B A C$ & 8493 & 8864 & 2.298 & 1.934 & \multicolumn{2}{|c|}{$0.364^{* * *}$} \\
\hline Growth & $S E A$ & 8836 & 8521 & 2.239 & 1.981 & \multicolumn{2}{|c|}{$0.258^{* * *}$} \\
\hline
\end{tabular}

Note: $(1)^{*}, * *$, and ${ }^{* * *}$ represent the significance levels of $10 \%, 5 \%$, and $1 \%$ respectively. (2) We use Table 3 to perform the mean-difference test between groups. (3) P50 means 50th Percentile, and CV means Coefficient of Variation.

\subsection{Correlation Analysis}

The correlation coefficient test results between variables are shown in Table 3 . Correlation analysis shows that the variables $B H C, D E I, B A C$, and $S E A$ were significantly and positively correlated with Growth $(p<0.01)$, indicating that a board's education level, board's professional background, and board's overseas experience were positively related to enterprise growth. In other words, board human capital was significantly and positively related to enterprise growth, which is in line with the preliminary conjecture of former theoretical analysis. The correlation between the variables in the matrix was small, which indicates that there was little possibility of multiple collinearities. To further test the multicollinearity problem, we investigated the variance inflation factor (VIF) value, which ranged from 2.92 to 2.99 , which was less than 10 , indicating that there was little concern regarding multicollinearity in the regression model. In addition, in order to avoid the heteroscedasticity problem, a clustering robust standard error regression was carried out in the regression. 
Table 3. Pearson correlation matrix between variables.

\begin{tabular}{|c|c|c|c|c|c|c|c|c|c|c|c|c|c|}
\hline Variable & Growth & BHC & $D E I$ & $B A C$ & SEA & IоTTOU & IOTTOE & SIZE & DOUL & SEC & $L E V$ & $A G E$ & $S T A$ \\
\hline BHC & $0.046^{* * *}$ & & & & & & & & & & & & \\
\hline$D E I$ & $0.119^{* * *}$ & $0.684^{* * *}$ & & & & & & & & & & & \\
\hline$B A C$ & $0.064^{* * *}$ & $0.637^{* * *}$ & $0.168^{* * *}$ & & & & & & & & & & \\
\hline$S E A$ & $0.132^{* * *}$ & $0.736^{* * *}$ & $0.276^{* * *}$ & $0.184^{* * *}$ & & & & & & & & & \\
\hline IОТTОU & $0.275^{* * *}$ & $0.128^{* * *}$ & $0.122 * * *$ & $0.066^{* * *}$ & $0.080^{* * *}$ & & & & & & & & \\
\hline IOTTOE & $-0.487^{* * *}$ & $0.125^{* * *}$ & 0.0300 & $0.170^{* * *}$ & $0.069^{* * *}$ & $0.145^{* * *}$ & & & & & & & \\
\hline SIZE & $0.138^{* * *}$ & $0.113^{* * *}$ & $0.150 * * *$ & $-0.044^{* * *}$ & $0.121^{* * *}$ & $-0.070^{* * *}$ & $-0.196^{* * *}$ & & & & & & \\
\hline DOUL & $-0.105^{* * *}$ & $0.084^{* * *}$ & 0.0050 & $0.109^{* * *}$ & $0.061^{* * *}$ & $0.059 * * *$ & $0.054^{* * *}$ & $-0.151^{* * *}$ & & & & & \\
\hline$S E C$ & $-0.454^{* * *}$ & $0.044^{* * *}$ & $0.057^{* * *}$ & -0.0120 & $0.043^{* * *}$ & $-0.115^{* * *}$ & $-0.123^{* * *}$ & $0.268^{* * *}$ & $-0.066^{* * *}$ & & & & \\
\hline LEV & $-0.058 * * *$ & $-0.106^{* * *}$ & $0.025^{* * *}$ & $-0.189 * * *$ & $-0.058^{* * *}$ & $-0.074^{* * *}$ & $-0.207^{* * *}$ & $0.472 * * *$ & $-0.149^{* * *}$ & $0.058^{* * *}$ & & & \\
\hline$A G E$ & $-0.269 * * *$ & $-0.052^{* * *}$ & $0.057^{* * *}$ & $-0.133 * * *$ & $-0.035^{* * *}$ & $-0.080^{* * *}$ & $-0.064^{* * *}$ & $0.185^{* * *}$ & $-0.089 * * *$ & $-0.169 * * *$ & $0.211^{* * *}$ & & \\
\hline STA & $-0.102 * * *$ & $-0.122 * * *$ & $0.095^{* * *}$ & $-0.178^{* * *}$ & $-0.159 * * *$ & $-0.044^{* * *}$ & $-0.154^{* * *}$ & $0.310 * * *$ & $-0.282 * * *$ & $0.195^{* * *}$ & $0.311^{* * *}$ & $0.172 * * *$ & \\
\hline GDP & $0.046^{* * *}$ & $-0.152 * * *$ & $-0.084 * * *$ & $-0.143 * * *$ & $-0.090 * * *$ & $0.083^{* * *}$ & $0.046^{* *}$ & $-0.121^{* * *}$ & $-0.049^{* * *}$ & $0.024 * * *$ & $0.054 * * *$ & $-0.192 * * *$ & $0.117^{* * *}$ \\
\hline
\end{tabular}

Note: ${ }^{*}, * *$ and ${ }^{* * *}$ represent the significance levels of $10 \%, 5 \%$, and $1 \%$ respectively. 


\subsection{Multiple Regression Results and Discussion}

OLS regression analysis was used to analyze the relationship between board human capital, ambidextrous innovation, and enterprise growth (Tables 4 and 5).

The Relationship between Board Human Capital and Enterprise Growth. First, we examined the impact of board human capital on enterprise growth (Model 1) and report the results in Table 4. In columns (1) and (2) of Table 4, we show that the variable BHC was positively correlated with Growth $(t=10.0344$, $p<0.01)$. That is, board human capital positively affected enterprise growth at a significant level of $1 \%$, indicating that the higher the level of board human capital, the more beneficial it was to enterprise growth. From an economic perspective, every standard deviation increase of board human capital (1.9780) resulted in an enterprise growth improvement equivalent to $6.42 \%(=0.0607 \times 1.9780 / 1.8696)$ of the sample standard deviation. It can be seen that board human capital had a significant positive relationship with enterprise growth in both a statistical and economic sense. Therefore, H1 was supported. Further, when examining the impact of the sub-index of board human capital on enterprise growth, we found that the estimated coefficient of the variable DEI was positive $(t=9.4364, p<0.01)$, and a board's education level had a positive impact on enterprise growth at a significance level of $1 \%$. From an economic perspective, every standard deviation increase of a board's education level (0.5178) resulted in an enterprise growth improvement equivalent to $6.01 \%(0.2170 \times 0.5178 / 1.8696)$ of the sample standard deviation. Therefore, a board's education level had a significantly positive impact on the enterprise growth, and H1a was supported. The estimated coefficient of variable $B A C$ was significantly negative $(t=-3.7042, p<0.01)$, indicating that the more directors with an $R \& D$, design, or marketing background on the board, the less likely an enterprise grew. This is inconsistent with the theoretical derivation, which may be due to the fact that the board of directors is composed of members from different professional fields that can hardly reach a unified opinion on the various opinions and suggestions provided during the meeting [47]. Moreover, the confusion and problems, such as communication, will appear frequently, and the emergence of these problems is not conducive to the formulation and implementation of enterprise strategic decision-making, thus threatening the survival and development of enterprises. Furthermore, the increasingly fierce global economic integration and market competition put forward higher requirements for the standardized management of enterprises, which not only requires senior executives to have a certain professional background, but also requires them to have professional management knowledge, management art, and organizational ability. When the number of directors with a background in "output function" in the board was more, it also meant the number of directors with professional management experience was less, which was not conducive to the development of enterprises in the long run. H1b was therefore rejected. The variable $S E A$ was positively correlated with Growth $(t=7.1741, p<0.01)$, where a board's overseas experience had a positive impact on enterprise growth at a significance level of 1\%. From an economic perspective, every standard deviation increase of a board's overseas experience (0.1129) resulted in an enterprise growth improvement equivalent to $4.60 \%(=0.7625 \times 0.1129 / 1.8696)$ of the sample standard deviation. To sum up, the more directors with overseas educational and work experience in the board, the more conducive it was to enterprise growth. H1c was therefore supported. 
Table 4. Results of regression analysis.

\begin{tabular}{|c|c|c|c|c|c|c|c|c|c|c|}
\hline & \multicolumn{2}{|c|}{ Corporate Growth } & \multicolumn{4}{|c|}{ Ambidextrous Innovation } & \multicolumn{4}{|c|}{ Corporate Growth } \\
\hline & Main Index & Sub-Indexes & Main Index & Sub-Indexes & Main Index & Sub-Indexes & Main Index & Sub-Indexes & Main Index & Sub-Indexes \\
\hline & (1) & (2) & (3) & (4) & (5) & (6) & (7) & (8) & (9) & (10) \\
\hline & Growth & Growth & IOTTOU & IOTTOU & IOTTOE & IOTTOE & Growth & Growth & Growth & Growth \\
\hline \multirow{2}{*}{$B H C$} & 0.0607 & & $0.0281^{* * *}$ & & $0.0590 * * *$ & & $0.0577^{* * *}$ & & $0.0570 * * *$ & \\
\hline & $(10.0344)$ & & $(5.6093)$ & & $(4.0222)$ & & $(5.3094)$ & & $(5.0828)$ & \\
\hline \multirow{2}{*}{$D E I$} & & $0.2170^{* * *}$ & & $0.0926^{* * *}$ & & -0.0257 & & $0.2404^{* * *}$ & & $0.1950 * * *$ \\
\hline & & $(9.4364)$ & & $(4.5698)$ & & $(-0.5592)$ & & $(5.7808)$ & & $(4.8451)$ \\
\hline \multirow{2}{*}{$B A C$} & & $-0.2452^{* * *}$ & & 0.0318 & & $0.6940 * * *$ & & -0.1780 & & -0.0738 \\
\hline & & $(-3.7042)$ & & $(0.6007)$ & & $(4.3086)$ & & $(-1.5079)$ & & $(-0.5910)$ \\
\hline \multirow{2}{*}{$S E A$} & & $0.7625^{* * *}$ & & $0.2326^{* * *}$ & & $0.6614^{* *}$ & & $0.5966^{* * *}$ & & $0.4580^{* *}$ \\
\hline & & $(7.1741)$ & & $(2.6023)$ & & $(2.3088)$ & & $(3.1544)$ & & $(2.4243)$ \\
\hline \multirow{2}{*}{ IOTTOU } & & & & & & & $0.1920 * * *$ & $0.1873^{* * *}$ & & \\
\hline & & & & & & & $(5.4379)$ & (5.3453) & & \\
\hline \multirow{2}{*}{ IOTTOE } & & & & & & & & & $0.0940 * * *$ & $0.0977^{* * *}$ \\
\hline & & & & & & & & & $(3.7612)$ & (3.9128) \\
\hline \multirow{2}{*}{ SIZE } & $-0.6227^{* * *}$ & $-0.6305^{* * *}$ & $0.0419^{* * *}$ & $0.0405^{* * *}$ & $-0.0671 * *$ & $-0.0643 * *$ & $-0.7215^{* * *}$ & $-0.7287^{* * *}$ & $-0.4904^{* * *}$ & $-0.4925^{* * *}$ \\
\hline & $(-40.6539)$ & $(-40.9380)$ & $(4.2134)$ & $(4.0569)$ & $(-2.3564)$ & $(-2.2700)$ & $(-26.0643)$ & $(-26.2623)$ & $(-14.5857)$ & $(-14.7627)$ \\
\hline \multirow{2}{*}{ DOUL } & $0.0610^{* *}$ & $0.0619 * *$ & $0.0417^{*}$ & $0.0413^{*}$ & 0.0431 & 0.0500 & 0.0770 & 0.0760 & 0.0000 & -0.0056 \\
\hline & (2.1114) & $(2.1462)$ & $(1.7920)$ & (1.7788) & $(0.5374)$ & $(0.6232)$ & $(1.5824)$ & $(1.5659)$ & $(0.0001)$ & $(-0.0872)$ \\
\hline \multirow{2}{*}{$S E C$} & $-1.7957^{* * *}$ & $-1.8188^{* * *}$ & $-0.6974^{* * *}$ & $-0.6945^{* * *}$ & -0.2583 & -0.2463 & $1.8842 * * *$ & $1.8863^{* * *}$ & $0.8916^{* * *}$ & $0.8907^{* * *}$ \\
\hline & $(-21.8107)$ & $(-22.1290)$ & $(-8.2043)$ & $(-8.1912)$ & $(-0.9856)$ & $(-0.9382)$ & $(9.5622)$ & $(9.5994)$ & $(4.6664)$ & $(4.6464)$ \\
\hline \multirow{2}{*}{$L E V$} & $0.1277^{* * *}$ & $0.0911^{* * *}$ & -0.0009 & -0.0082 & $-1.1725^{* * *}$ & $-1.1455^{* * *}$ & $-2.2726^{* * *}$ & $-2.2961^{* * *}$ & $-1.6273^{* * *}$ & $-1.6421^{* * *}$ \\
\hline & (3.9425) & $(2.8243)$ & $(-0.0146)$ & $(-0.1319)$ & $(-6.6075)$ & $(-6.4277)$ & $(-15.3928)$ & $(-15.5470)$ & $(-9.4086)$ & $(-9.6370)$ \\
\hline \multirow{2}{*}{$A G E$} & $0.9888^{* * *}$ & $0.9934^{* * *}$ & -0.0458 & -0.0513 & $-0.4132 * * *$ & $-0.3872 * * *$ & 0.0455 & 0.0182 & -0.0274 & -0.0488 \\
\hline & $(10.7459)$ & $(10.8621)$ & $(-1.3729)$ & $(-1.5343)$ & $(-4.3620)$ & $(-4.0765)$ & $(0.6820)$ & $(0.2727)$ & $(-0.3713)$ & $(-0.6533)$ \\
\hline \multirow{2}{*}{ STA } & $-0.2196^{* * *}$ & $-0.2299 * * *$ & 0.0088 & 0.0022 & $-0.2322 * * *$ & $-0.2228^{* * *}$ & $-0.1937^{* * *}$ & $-0.2089 * * *$ & $-0.0969 * *$ & $-0.1007^{* *}$ \\
\hline & $(-9.0338)$ & $(-9.2348)$ & $(0.3813)$ & $(0.0918)$ & $(-3.3147)$ & $(-3.1755)$ & $(-4.2092)$ & $(-4.3657)$ & $(-2.0260)$ & $(-2.0516)$ \\
\hline
\end{tabular}


Table 4. Cont

\begin{tabular}{|c|c|c|c|c|c|c|c|c|c|c|}
\hline & \multicolumn{2}{|c|}{ Corporate Growth } & \multicolumn{4}{|c|}{ Ambidextrous Innovation } & \multicolumn{4}{|c|}{ Corporate Growth } \\
\hline & Main Index & Sub-Indexes & Main Index & Sub-Indexes & Main Index & Sub-Indexes & Main Index & Sub-Indexes & Main Index & Sub-Indexes \\
\hline & (1) & (2) & (3) & (4) & (5) & (6) & (7) & (8) & (9) & (10) \\
\hline & Growth & Growth & IOTTOU & IOTTOU & IOTTOE & IOTTOE & Growth & Growth & Growth & Growth \\
\hline \multirow{2}{*}{$G D P$} & $0.8396^{* * *}$ & $0.8687^{* * *}$ & $0.4503 * *$ & $0.4625^{* *}$ & 0.7925 & 0.7633 & 0.8150 & 0.8618 & -0.7867 & -0.7676 \\
\hline & $(2.6127)$ & $(2.7054)$ & $(2.1033)$ & $(2.1633)$ & $(1.0400)$ & $(0.9977)$ & $(1.2815)$ & $(1.3556)$ & $(-0.9957)$ & $(-0.9781)$ \\
\hline Year/IND & $\mathrm{Y}$ & $\mathrm{Y}$ & Y & Y & Y & $\mathrm{Y}$ & Y & Y & $\mathrm{Y}$ & Y \\
\hline \multirow{2}{*}{ _cons } & $14.8822^{* * *}$ & $14.5916^{* * *}$ & 0.1368 & -0.0791 & $2.8357^{* * *}$ & $2.6104^{* * *}$ & $17.0990 * * *$ & $16.6805^{* * *}$ & $12.0881^{* * *}$ & $11.6776^{* * *}$ \\
\hline & $(48.8389)$ & $(47.2012)$ & $(0.4565)$ & $(-0.2595)$ & $(3.6644)$ & (3.4293) & $(23.3873)$ & $(22.7191)$ & (16.5577) & $(16.4191)$ \\
\hline$N$ & 17357 & 17357 & 5796 & 5796 & 2823 & 2823 & 5796 & 5796 & 2823 & 2823 \\
\hline$r 2 \_a$ & 0.4620 & 0.4648 & 0.1922 & 0.1930 & 0.3097 & 0.3119 & 0.4904 & 0.4924 & 0.4586 & 0.4606 \\
\hline$F$ & 293.7056 & 279.4808 & 24.6360 & 23.1309 & 43.8956 & 43.6087 & 117.3294 & 111.8225 & 49.6169 & 47.8545 \\
\hline
\end{tabular}

Note: $(1)^{*}, * *$, and ${ }^{* * *}$ represent the significance levels of $10 \%, 5 \%$, and $1 \%$, respectively. (2) The values in parentheses are $t$-statistics after correcting for heteroscedasticity. 
Table 5. Results of the regression analysis of the binary innovation matching model.

\begin{tabular}{|c|c|c|c|c|}
\hline & $\begin{array}{c}\text { (1) } \\
\text { Growth }\end{array}$ & $\begin{array}{c}(2) \\
\text { Growth }\end{array}$ & $\begin{array}{c}\text { (3) } \\
\text { Growth }\end{array}$ & $\begin{array}{c}\text { (4) } \\
\text { Growth }\end{array}$ \\
\hline \multirow{2}{*}{ IOTTOU } & $0.2034^{* * *}$ & & & \\
\hline & $(5.7919)$ & & & \\
\hline \multirow{2}{*}{ IOTTOE } & & $0.1000 * * *$ & & \\
\hline & & $(4.0133)$ & & \\
\hline \multirow{2}{*}{ IOTTOU × IOTTOE } & & & 0.0033 & \\
\hline & & & $(0.1715)$ & \\
\hline \multirow{2}{*}{ | IOTTOU - IOTTOE | } & & & & $0.0680^{* *}$ \\
\hline & & & & $(2.0907)$ \\
\hline \multirow{2}{*}{ SIZE } & $-0.7105^{* * *}$ & $-0.4703^{* * *}$ & $-0.4743^{* * *}$ & $-0.4706^{* * *}$ \\
\hline & $(-25.6524)$ & $(-14.4574)$ & $(-12.4424)$ & $(-12.2133)$ \\
\hline \multirow{2}{*}{ DOUL } & $0.0909^{*}$ & -0.0015 & 0.0619 & 0.0613 \\
\hline & (1.8605) & $(-0.0233)$ & $(0.7100)$ & $(0.7159)$ \\
\hline \multirow{2}{*}{$S E C$} & $1.9020^{* * *}$ & $0.9735^{* * *}$ & $1.1045^{* * *}$ & $1.0489 * * *$ \\
\hline & $(9.6745)$ & $(5.1049)$ & $(4.9875)$ & $(4.5760)$ \\
\hline \multirow{2}{*}{$L E V$} & $-2.3088^{* * *}$ & $-1.6554^{* * *}$ & $-1.9319 * * *$ & $-1.8725^{* * *}$ \\
\hline & $(-15.6338)$ & $(-9.5673)$ & $(-9.3412)$ & $(-9.5439)$ \\
\hline \multirow{2}{*}{$A G E$} & 0.0072 & -0.0554 & $-0.1735^{* *}$ & $-0.1535^{*}$ \\
\hline & $(0.1096)$ & $(-0.7541)$ & $(-2.0903)$ & $(-1.8410)$ \\
\hline \multirow{2}{*}{ STA } & $-0.1945^{* * *}$ & $-0.0883^{*}$ & -0.0913 & -0.0813 \\
\hline & $(-4.1988)$ & $(-1.8290)$ & $(-1.5037)$ & $(-1.3657)$ \\
\hline \multirow{2}{*}{ GDP } & 0.8398 & -0.7598 & -0.0013 & -0.0985 \\
\hline & $(1.3220)$ & $(-0.9715)$ & $(-0.0012)$ & $(-0.0909)$ \\
\hline Year/IND & $\mathrm{Y}$ & $\mathrm{Y}$ & $\mathrm{Y}$ & $\mathrm{Y}$ \\
\hline \multirow{2}{*}{ _cons } & $16.9170^{* * *}$ & $11.6583^{* * *}$ & $11.9160^{* * *}$ & $11.8401^{* * *}$ \\
\hline & $(23.0408)$ & $(16.3150)$ & $(13.4162)$ & (13.2999) \\
\hline$N$ & 5796 & 2823 & 1725 & 1725 \\
\hline$r 2 \_a$ & 0.4878 & 0.4533 & 0.4784 & 0.4831 \\
\hline$F$ & 118.8685 & 50.5730 & 33.6066 & 33.7751 \\
\hline
\end{tabular}

Note: $(1)^{*}, * *$, and ${ }^{* * *}$ represent the significance levels of $10 \%, 5 \%$, and $1 \%$, respectively. (2) The values in parentheses are $t$-statistics after correcting heteroscedasticity.

The Relationship between Board Human Capital and Ambidextrous Innovation. According to Model 2 , the relationship was tested between board human capital and ambidextrous innovation, and the estimated results are shown in Table 4. In columns (3)-(6) of Table 4, we show that Model 2 contained the main effect of board human capital and ambidextrous innovation, which was mainly used to verify hypothesis $\mathrm{H} 2$. The results show that the variable BHC was positively correlated with IOTTOU and IOTTOE $(t=5.6093, p<0.01 ; t=4.0222, p<0.01)$, where board human capital positively affected ambidextrous innovation at a $1 \%$ significance level, indicating that the higher the level of board human capital, the more conducive it was toward improving the level of corporate binary innovation. Therefore, H2 and H3 were supported. Due to the difference between exploitation innovation and exploratory innovation in the demand for resources and capabilities, we further studied the impact of the sub-index of board human capital on ambidextrous innovation, and found that the variables $D E I$ 
and SEA were positively correlated with IOTTOU $(t=4.5698, p<0.01 ; t=2.6023, p<0.01)$, but BAC was not significantly correlated with $\operatorname{IOTTOU}(t=0.6007, p>0.1)$. This suggests that a board's education level and overseas experience have a positive impact on the exploitation innovation at a significance level of $1 \%$. This shows that the higher the education level of directors, the more overseas experience directors have, the more conducive to improving the utilization of existing knowledge and technology, leading to achieving technological progress and product optimization, and promoting the level of exploitation innovation. However, a board's professional background had no significant positive correlation with exploitation innovation, which is inconsistent with the theoretical derivation. This may be related to the nature of exploitation innovation. Exploitation innovation requires sufficient knowledge and skills to improve and optimize existing products, which is independent of whether directors have the background of "export function." It can be seen that $\mathrm{H} 2 \mathrm{a}$ and $\mathrm{H} 2 \mathrm{c}$ were supported and $\mathrm{H} 2 \mathrm{~b}$ was rejected. The variables $B A C$ and $S E A$ were positively correlated with IOTTOE $(t=4.3086$, $p<0.01 ; t=2.3088, p<0.05)$, while DEI was negatively correlated with IOTTOE $(t=-0.5592, p>0.1)$, suggesting that a board's professional background and overseas experience had a positive impact on exploratory innovation at a significance level of $1 \%$ and $5 \%$, respectively, indicating that the more background in "output function" and overseas experience directors had, the more conducive they were to acquiring new knowledge and skills and to achieving a breakthrough innovation. However, a board's education level was negatively correlated with exploratory innovation and was not significant, which is inconsistent with the theoretical deduction. This may be related to the highly educated directors' strong sense of risk aversion and lower participation in high-risk, high-return R\&D and investment projects. Therefore, $\mathrm{H} 3 \mathrm{~b}$ and $\mathrm{H} 3 \mathrm{c}$ were supported, and $\mathrm{H} 3 \mathrm{a}$ was rejected.

The Relationship between Ambidextrous Innovation and Enterprise Growth. The relationship between ambidextrous innovation and enterprise growth was tested according to Models 3 and 4 , and the estimated results are shown in Table 5. In the columns (1)-(4) of Table 5, we show that Model 3 mainly validated whether ambidextrous innovation can promote enterprise growth, and was used to test $\mathrm{H} 4 \mathrm{a}$ and $\mathrm{H} 4 \mathrm{~b}$. The regression results show that both IOTTOU and IOTTOE were positively correlated with Growth $(t=5.7919, p<0.01 ; t=4.0133, p<0.01)$, suggesting that both exploitation innovation and exploratory innovation had a positive impact on enterprise growth at a significance level of $1 \%$. Therefore, H4a and H4b were supported. Model 4 mainly verified the influence of the matching mode of binary innovation on enterprise growth, which was used to test H5a and H5b. The regression results show that the balance effect of exploitation innovation and exploratory innovation had a weak but significantly positive impact on enterprise growth $(t=2.0907, p<0.05)$, while the product effect had little significant association with enterprise growth $(t=0.1715, p>0.1)$. Therefore, H5a was supported and $\mathrm{H} 5 \mathrm{~b}$ was rejected.

The Mediating Effect of Ambidextrous Innovation. Using the methods of Wen et al. [48] and combining Models 1, 2, and 5, we tested whether ambidextrous innovation had an intermediary effect on the relationship between board human capital and enterprise growth according to the following procedures. The first step was to test whether the coefficient $\beta_{1,1}$ of Model 1 was statistically significant. If the subsequent test was established, it was a mediating effect; otherwise, it was a masking effect. In the second step, the coefficient $\beta_{2,1}$ of Model 2 and the coefficient $\beta_{5,5}$ of Model 5 were tested successively. If both were significant, it was an indirect effect, and the fourth step was carried out; otherwise, the next step was carried out. In the third step, we used the bootstrap method to test $H 0: \beta_{2,1} \cdot \beta_{5,5}=0$. If the result was significant, it was an indirect effect, and then proceeded to the next step; otherwise, the indirect effect was not significant and we stopped the analysis. The fourth step was to test the coefficient $\beta_{5,1}$ of Model 5. If it was significant, the direct effect was significant and the next step was carried out; otherwise, the direct effect was not significant and only the intermediary effect existed. The fifth step was to compare $\beta_{2,1} \cdot \beta_{5,5}$ and $\beta_{5,1}$. If the sign was the same, they belonged to a partial mediation effect; if not, it was a masking effect. Based on the above research methods and the regression results in columns (1)-(9) of Table 4, we found that in the previous analysis, it was known that $\beta_{1,1}$ and $\beta_{2,1}$ were significant. After adding exploitation innovation into the regression equation, the regression 
coefficient of exploitation innovation on enterprise growth in column (7) was positively correlated at the $1 \%$ significance level $(t=5.4379, p<0.01)$ where $\beta_{5,5}$ was significant. Moreover, by comparing columns (1) and (7), the regression coefficient of the board human capital was reduced to some degree, but it was still positively correlated at the significant level of $1 \%(t=5.3094, p<0.01)$; that is, $\beta_{5,1}$ was significant. Since the signs of $\beta_{2,1} \cdot \beta_{5,5}$ and $\beta_{5,1}$ were the same, exploitation innovation played an intermediary role in the relationship between board human capital and enterprise growth. Next, we considered the mediating effects of exploratory innovation. Similar to the analysis of the mediating effect of exploitation innovation, exploratory innovation also played a partial mediating role in the relationship between board human capital and enterprise growth. Therefore, ambidextrous innovation played an intermediary role in board human capital and enterprise growth, and $\mathrm{H} 6$ was supported.

Further, we examined the mediating effect of ambidextrous innovation on the index of board human capital and enterprise growth, and the results are shown in columns (2)-(10) of Table 4. We found that exploitation innovation played part of the mediating effect on a board's education level and enterprise growth, while exploratory innovation had no significant indirect effect on a board's education level and enterprise growth. The indirect effect of exploitation innovation on a board's professional background and enterprise growth was not significant, and exploratory innovation played a covering effect on a board's professional background and enterprise growth. Ambidextrous innovation played part of the mediating effect between a board's overseas experience and enterprise growth (Considering the mediating effect of IOTTOE on DEI and Growth, since $\beta_{2,2}<0$, the bootstrap method was used to test and $p=0.441$ was obtained. Therefore, the indirect effect was not significant. Considering the mediating effect of IOTTOE between BAC and Growth, we adopted the bootstrap test and obtained $p=0.000$; that is, the indirect effect was significant, but there was a masking effect due to the difference between $\beta_{2,3} \cdot \beta_{5,5}$ and $\beta_{5,3}$. Similarly, the indirect effect of IOTTOU on BAC and Growth was not significant). In conclusion, H6c was supported, H6a was partially supported, and H6b was rejected.

\subsection{Robustness Test}

In order to verify the reliability of the regression results, we conducted the robustness tests from the following aspects.

Problem with Measurement Error. The growth rate of business income was adopted as a substitute indicator for growth. Considering the cumulative effect of board human capital, we take $t+1$ period and $t+2$ period for enterprise growth, and then conducted the regression of the main effect of board human capital on enterprise growth. The specific results of the indicator replacement are shown in columns (1) and (2) of Table 6. We found no matter whether $t+1$ period or $t+2$ period was applied, board human capital still had a significantly positive impact on enterprise growth $(t=2.6780, p<0.01$; $t=2.4669, p<0.05$ ).

Problems with Legacy Variables. Since the characteristics of enterprises also affected enterprise growth, there could be a problem of legacy variables; therefore, we adopted the placebo test to examine this possibility. Specifically, we randomly sorted board human capital in the sample before the regression analysis. If the result after regression was no longer significant, it indicated that board human capital was related to enterprise growth. On the contrary, if the result was still significant, it indicated that the basic regression result may have been caused by omitted variables. The results of the placebo test are shown in column (3) of Table 6, with little association between board human capital after reordering and enterprise growth, indicating that board human capital promoted enterprise growth, and the results were not caused by other omitted variables.

Problems with Reverse Causality. In the theoretical derivation part, it was concluded that the higher the board human capital is, the better it is at improving enterprise growth. However, enterprises with higher growth may also tend to choose directors with a higher human capital level to form the board of directors. There may be a causal endogeneity problem between board human capital and enterprise growth. In order to reduce the interference of endogeneity problems, we chose the average 
board human capital grouped by year and industry as the instrumental variable (IV). The average board human capital in the same industry and year was related to board human capital but did not affect enterprise growth. Subsequently, we used a two-stage least squares regression (2SLS) to test the weak instrumental variables. The results showed that Shea's Partial $R^{2}$ was less than 0.01 , but the $F$ statistic was 85.7294 , and the $p$-value of the $F$ statistic is 0 . Therefore, the average board human capital was not a weak instrumental variable. Column (4) in Table 6 gives the regression results of the first stage, showing that the estimated coefficient of the instrumental variable (IV) was significantly positive $(t=0.1000, p<0.01)$. Column (5) is the second-stage regression result, showing that even after considering endogeneity problems, board human capital was still significantly positively associated with enterprise growth at significance the level of $1 \%(t=0.0790, p<0.01)$, suggesting that board human capital had a significantly positive impact on enterprise growth.

Table 6. Robustness test regression results.

\begin{tabular}{|c|c|c|c|c|c|}
\hline & (1) & (2) & (3) & (4) & (5) \\
\hline & F. Growth & F2. Growth & Growth & BHC & Growth \\
\hline \multirow{2}{*}{$B H C$} & $0.0056^{* * *}$ & $0.0056^{* *}$ & & & $0.156^{* *}$ \\
\hline & $(2.6780)$ & $(2.4669)$ & & & $(0.0790)$ \\
\hline \multirow{2}{*}{$r-B H C$} & & & -0.0037 & & \\
\hline & & & $(-0.7189)$ & & \\
\hline \multirow{2}{*}{$i v$} & & & & $0.929^{* * *}$ & \\
\hline & & & & $(0.100)$ & \\
\hline \multirow{2}{*}{$S I Z E$} & $-0.0410^{* * *}$ & $-0.0522 * * *$ & $-0.6083^{* * *}$ & $0.233 * * *$ & $-0.645^{* * *}$ \\
\hline & $(-7.7092)$ & $(-9.4162)$ & $(-39.8576)$ & $(0.0147)$ & $(0.0238)$ \\
\hline \multirow{2}{*}{ DOUL } & 0.0114 & -0.0018 & $0.0692 * *$ & $0.135^{* * *}$ & 0.0480 \\
\hline & (1.1775) & $(-0.1617)$ & $(2.3938)$ & $(0.0350)$ & $(0.0306)$ \\
\hline \multirow{2}{*}{$L E V$} & $0.1314^{* * *}$ & 0.0438 & $-1.8376^{* * *}$ & $-0.658^{* * *}$ & $-1.731^{* * *}$ \\
\hline & $(4.4741)$ & $(1.4252)$ & $(-22.2724)$ & $(0.0820)$ & $(0.0984)$ \\
\hline \multirow{2}{*}{$A G E$} & $-0.0280^{* * *}$ & -0.0159 & $0.0915^{* * *}$ & $-0.597 * * *$ & $0.184^{* * *}$ \\
\hline & $(-2.6019)$ & $(-1.3648)$ & $(2.8590)$ & $(0.0421)$ & $(0.0573)$ \\
\hline \multirow{2}{*}{ SEC } & 0.0250 & 0.0603 & $1.0292 * * *$ & $0.670^{* * *}$ & $0.925^{* * *}$ \\
\hline & $(0.7527)$ & $(1.6372)$ & (11.1710) & $(0.129)$ & $(0.107)$ \\
\hline \multirow{2}{*}{ STA } & $-0.0557^{* * *}$ & $-0.0477^{* * *}$ & $-0.2328^{* * *}$ & $-0.210 * * *$ & $-0.199 * * *$ \\
\hline & $(-5.8901)$ & $(-4.6853)$ & $(-9.5398)$ & $(0.0337)$ & $(0.0297)$ \\
\hline \multirow{2}{*}{ GDP } & 0.0924 & -0.1655 & 0.7943 ** & $-0.703^{*}$ & $0.906^{* * *}$ \\
\hline & $(0.7333)$ & $(-1.1045)$ & $(2.4688)$ & $(0.400)$ & $(0.328)$ \\
\hline Year/IND & $\mathrm{Y}$ & $\mathrm{Y}$ & $\mathrm{Y}$ & $\mathrm{Y}$ & $\mathrm{Y}$ \\
\hline \multirow{2}{*}{ _cons } & $0.9263^{* * *}$ & $1.4490^{* * *}$ & $14.6411^{* * *}$ & $-3.096^{* * *}$ & $15.26^{* * *}$ \\
\hline & $(8.3685)$ & $(12.2863)$ & $(48.1461)$ & $(0.348)$ & $(0.432)$ \\
\hline$N$ & 14,684 & 12,598 & 17,357 & 17,357 & 17,357 \\
\hline$r 2 \_a$ & 0.0431 & 0.0427 & 0.4585 & 0.172 & 0.455 \\
\hline$F$ & 17.2305 & 16.3214 & 290.3378 & - & - \\
\hline
\end{tabular}




\section{Further Discussion: The Influencing Factors of Enterprise Growth and Ambidextrous Innovation}

The above analysis has passed the $\mathrm{H} 1, \mathrm{H} 2, \mathrm{H} 3, \mathrm{H} 4 \mathrm{a}$, and $\mathrm{H} 4 \mathrm{~b}$ tests, which further verifies and enriches the theoretical analysis framework of "enterprise resources-enterprise capabilities-enterprise growth." However, as a typical internal orientation theory, it excessively weakens the influence of external environmental factors on enterprise growth. When enterprises choose a growth strategy, they will carry out a corresponding risk prediction and environmental assessment, and pay more attention to industry differences and market competition. Existing studies show the resource and capacity requirements of industries with different factor intensities are different. For example, in labor-intensive, capital-intensive, and technology-intensive industries, due to the obvious difference in the importance of technology, the investment in technological innovation of each industry is not the same [49]. Among different factor intensive industries, will there be industry differences in the promotion effect of board human capital and ambidextrous innovation on enterprise growth? In addition, the R\&D resources investment of enterprises is not only influenced by the preferences of the board of directors or management or the balance of power, but also by the industry characteristics and market concentration and other macro factors [50,51]. Similarly, will the impact of board human capital on ambidextrous innovation be affected by industry differences or market competition? Based on the above considerations, we proceeded with the influencing factors of enterprise growth and innovation respectively, and performed a grouping regression on the basis of Models 2, 3, and 4, and further differentiation analysis of the above assumptions.

\subsection{Analysis of Factors Affecting Enterprise Growth}

Based on the industry classification of the China Securities Regulatory Commission in 2001, we removed the insurance and financial industries, and ranked the manufacturing industry with other industries. We finally obtained 21 industries. Drawing on the cluster analysis method of Lu et al. [49], samples were divided into labor-intensive, capital-intensive, and technology-intensive types according to the factor density. At the same time, according to the "Management Measures for the Recognition of High-Tech Enterprises" promulgated by China in 2008, the technology-intensive industries were identified as high-tech industries, and other industries were identified as non-high-tech industries. The specific classification results are shown in Table 7.

Table 7. Classification of non-high-tech industries and high-tech industries.

\begin{tabular}{|c|c|c|}
\hline \multirow{3}{*}{ High-tech industry } & C5 (Electronic) & C9 (Other manufacturing) \\
\hline & $\begin{array}{l}\text { C7 (Machinery, equipment, } \\
\text { and instruments) }\end{array}$ & $\begin{array}{l}\text { G (Information technology } \\
\text { industry) }\end{array}$ \\
\hline & $\begin{array}{l}\text { C8 (Medicine and } \\
\text { biological products) }\end{array}$ & \\
\hline \multirow{8}{*}{ Non-high-tech industry } & $\begin{array}{c}\text { A (Agriculture, forestry, animal } \\
\text { husbandry, and fishery) }\end{array}$ & $\begin{array}{l}\mathrm{D} \text { (Electricity, gas, and water } \\
\text { production and supply) }\end{array}$ \\
\hline & B (Extractive industry) & E (Construction industry) \\
\hline & C0 (Food and drink) & $\begin{array}{l}\text { F (Transportation and } \\
\text { warehousing) }\end{array}$ \\
\hline & C1 (Textile, clothing, and fur) & $\mathrm{H}$ (Wholesale and retail trade) \\
\hline & C2 (Wood and furniture) & J (Real estate industry) \\
\hline & C3 (Paper and printing) & K (Social service industry) \\
\hline & $\begin{array}{l}\text { C4 (Petroleum, chemical, } \\
\text { and plastic) }\end{array}$ & $\begin{array}{l}\text { L (Communication and } \\
\text { cultural industry) }\end{array}$ \\
\hline & C6 (Metal and non-metal) & M (Miscellaneous) \\
\hline
\end{tabular}


Board Human Capital and Enterprise Growth: Comparison by Industry. First of all, we compared the differences between board human capital and enterprise growth in different industries. The regression results in columns (1) and (2) of Table 8 show that, consistent with the regression results of the whole sample, the estimated coefficient of board human capital $(B H C)$ in both high-tech and non-high-tech industries were significantly positive $(t=7.4060, p<0.01 ; t=7.4175, p<0.01)$. In order to further test whether there were differences in the coefficients between groups after the grouping regression, we conducted a SUR (Seemingly Unrelated Regression) test based on the seemingly unrelated model. The empirical value P1 in columns (1) and (2) of Table 8 was less than 0.1, which indicates that the promotion effect of board human capital on enterprise growth was significantly different between industries, and the promotion effect was more significant in the high-tech industry. Consistent with the existing research, due to the outstanding characteristics of high innovation and high growth of the high-tech industry, its developmental results often rely on the high-quality talents of enterprises, including the senior management talents of enterprises. Therefore, the contribution of board human capital to the growth of high-tech industries was much higher than that of non-high-tech industries. Further, the regression results in columns (3) and (4) of Table 8 show that, consistent with the whole sample regression results, in both high-tech and non-high-tech industries, a board's education level $(D E I)$ and overseas experience (SEA) were positively correlated with enterprise growth, and there was no significant industry difference (empirical values P2 and P4 corresponding to columns (3) and (4) in Table 8 were all greater than 0.1), indicating that a board's education level and overseas experience were of great significance for improving enterprise growth. There were significant industry differences in the negative correlation between board's professional background and enterprise growth (the empirical value P3, corresponding to columns (3) and (4) in Table 8, was less than 0.1), which was more significant in non-high-tech industries. This may have been because non-high-tech industries are more risk-averse than high-tech ones. However, directors with a background in "output function" often face the pressure of product market and development, and they tend to try high-risk, high-return investment projects. Therefore, the more directors with an "output function" background, the higher the risk of a strategic decision made by the board of directors, which was not conducive to the long-term development of the enterprise. In this case, the negative correlation between a board's professional background and enterprise growth was more significant in non-high-tech industries.

Ambidextrous Innovation and Enterprise Growth: Comparison by Industry. We compared the difference between ambidextrous innovation and enterprise growth in different industries. The regression results in columns (5)-(8) of Table 8 show that, consistent with the whole sample regression results, the estimated coefficients of exploitative innovation were significant in both high-tech and non-high-tech industries $(t=5.3323, p<0.01 ; t=6.8835, p<0.01)$. For this reason, we further tested whether there were differences in coefficients between groups. The results show that there were significant industry differences in the promotion effect of exploitative innovation on enterprise growth (the empirical value P1 corresponding to columns (5) and (6) in Table 8 was less than 0.1), which was more significant in non-high-tech industries. This shows that although both industries attached importance to the optimization of existing technologies and products, non-high-tech enterprises were more dependent on exploitative innovation due to the existence of serious exploratory innovation shortcomings, further indicating the importance of exploitative innovation to the growth of non-high-tech enterprises. In the high-tech industry, the estimated coefficient of exploratory innovation was significantly positive $(t=6.4603, p<0.01)$, but this significant relationship did not exist in the non-high-tech industry $(t=1.4586, p>0.1)$ where there was a significant industry difference in the role of exploratory innovation in promoting enterprise growth, which was more significant in the high-tech industry. This is consistent with the actual situation. Due to the low level of non-high-tech industries, the lack of innovation resources and the insufficient investment in innovation, it is difficult to break through the existing knowledge and technology and open up new markets. Therefore, exploratory innovation has not become the main driving force for the growth of non-high-tech enterprises. 
Table 8. Board human capital and enterprise growth: comparison by industry.

\begin{tabular}{|c|c|c|c|c|c|c|c|c|}
\hline & \multicolumn{4}{|c|}{ BHC-Growth } & \multicolumn{4}{|c|}{ IOTTOU(IOTTOE)-Growth } \\
\hline & High-Tech & Non-High-Tech & High-Tech & Non-High-Tech & High-Tech & Non-High-Tech & High-Tech & Non-High-Tech \\
\hline & (1) & (2) & (3) & (4) & (5) & (6) & (7) & (8) \\
\hline & Growth & Growth & Growth & Growth & Growth & Growth & Growth & Growth \\
\hline \multirow{2}{*}{ BHC } & $0.0729^{* * *}$ & $0.0512 * * *$ & & & & & & \\
\hline & $(7.4060)$ & $(7.4175)$ & & & & & & \\
\hline \multirow{2}{*}{$D E I$} & & & $0.2662^{* * *}$ & $0.1915^{* * *}$ & & & & \\
\hline & & & $(6.6527)$ & $(7.5327)$ & & & & \\
\hline \multirow{2}{*}{$B A C$} & & & -0.1325 & $-0.3569 * * *$ & & & & \\
\hline & & & $(-1.3130)$ & $(-4.5530)$ & & & & \\
\hline \multirow{2}{*}{$S E A$} & & & $0.8116^{* * *}$ & $0.7086^{* * *}$ & & & & \\
\hline & & & $(4.8368)$ & $(5.8571)$ & & & & \\
\hline \multirow{2}{*}{ IOTTOU } & & & & & $0.1756^{* * *}$ & $0.3932 * * *$ & & \\
\hline & & & & & $(5.3323)$ & $(6.8835)$ & & \\
\hline \multirow{2}{*}{ IOTTOE } & & & & & & & $0.1294^{* * *}$ & 0.0325 \\
\hline & & & & & & & $(6.4603)$ & $(1.4586)$ \\
\hline \multirow{2}{*}{ SIZE } & $-0.7105^{* * *}$ & $-0.5694^{* * *}$ & $-0.7182 * * *$ & $-0.5775^{* * *}$ & $-0.7985^{* * *}$ & $-0.5988^{* * *}$ & $-0.6204^{* * *}$ & $-0.3604^{* * *}$ \\
\hline & $(-36.9266)$ & $(-44.9897)$ & $(-37.2055)$ & $(-45.5374)$ & $(-25.6138)$ & $(-20.8058)$ & $(-17.2792)$ & $(-15.3996)$ \\
\hline \multirow{2}{*}{ DOUL } & 0.0322 & $0.0863 * *$ & 0.0312 & $0.0896^{* * *}$ & 0.0780 & 0.1029 & -0.0733 & 0.0086 \\
\hline & $(0.7897)$ & $(2.5747)$ & $(0.7666)$ & (2.6835) & $(1.2404)$ & $(1.6126)$ & $(-0.7306)$ & $(0.1230)$ \\
\hline \multirow{2}{*}{ SEC } & $1.3353 * * *$ & $0.7584^{* * *}$ & $1.3447^{* * *}$ & $0.7609^{* * *}$ & $2.2262 * * *$ & $1.4519^{* * *}$ & $0.8738^{* *}$ & $0.9225^{* * *}$ \\
\hline & $(7.4474)$ & $(6.7631)$ & $(7.5177)$ & $(6.8082)$ & $(7.3632)$ & $(5.6102)$ & $(2.5124)$ & $(4.3291)$ \\
\hline \multirow{2}{*}{$L E V$} & $-1.8625^{* * *}$ & $-1.7720 * * *$ & $-1.9223 * * *$ & $-1.7690 * * *$ & $-2.0487^{* * *}$ & $-2.6093^{* * *}$ & $-1.2065^{* * *}$ & $-2.0004^{* * *}$ \\
\hline & $(-17.0890)$ & $(-23.5617)$ & $(-17.5914)$ & $(-23.5953)$ & $(-11.2052)$ & $(-15.5729)$ & $(-5.2508)$ & $(-13.7748)$ \\
\hline \multirow{2}{*}{$A G E$} & $0.1061 * *$ & $0.1588^{* * *}$ & 0.0791 & $0.1135^{* * *}$ & 0.0344 & 0.0011 & -0.1267 & 0.0439 \\
\hline & $(2.0330)$ & $(4.0156)$ & $(1.5105)$ & $(2.8535)$ & $(0.3785)$ & $(0.0130)$ & $(-0.8878)$ & $(0.5075)$ \\
\hline \multirow{2}{*}{ STA } & $-0.1291 * * *$ & $-0.2700^{* * *}$ & $-0.1364^{* * *}$ & $-0.2843^{* * *}$ & $-0.1909 * * *$ & $-0.2280 * * *$ & $-0.1665^{* *}$ & -0.0371 \\
\hline & $(-2.9550)$ & $(-9.0948)$ & $(-3.0781)$ & $(-9.4249)$ & $(-2.6094)$ & $(-3.4634)$ & $(-2.0911)$ & $(-0.6612)$ \\
\hline
\end{tabular}


Table 8. Cont.

\begin{tabular}{|c|c|c|c|c|c|c|c|c|}
\hline & \multicolumn{4}{|c|}{ BHC-Growth } & \multicolumn{4}{|c|}{ IOTTOU(IOTTOE)-Growth } \\
\hline & High-Tech & Non-High-Tech & High-Tech & Non-High-Tech & High-Tech & Non-High-Tech & High-Tech & Non-High-Tech \\
\hline & (1) & (2) & (3) & (4) & (5) & (6) & (7) & (8) \\
\hline & Growth & Growth & Growth & Growth & Growth & Growth & Growth & Growth \\
\hline \multirow{2}{*}{$G D P$} & 0.4346 & $0.8087^{* *}$ & 0.4539 & $0.8454^{* *}$ & 0.6882 & 0.7549 & -0.7605 & -1.0149 \\
\hline & $(0.7765)$ & $(2.2331)$ & $(0.8125)$ & $(2.3423)$ & $(0.8083)$ & $(1.0436)$ & $(-0.6579)$ & $(-1.5004)$ \\
\hline Year/IND & $\mathrm{Y}$ & Y & Y & Y & Y & Y & Y & $\mathrm{Y}$ \\
\hline \multirow{2}{*}{ _cons } & $16.8499 * * *$ & $13.8312 * * *$ & $16.3922 * * *$ & $13.6497^{* * *}$ & $19.5368^{* * *}$ & $14.4517^{* * *}$ & $15.9327^{* * *}$ & $9.7328^{* * *}$ \\
\hline & $(39.3943)$ & $(47.3334)$ & $(37.7496)$ & $(45.9696)$ & $(25.9331)$ & $(16.0864)$ & $(14.4968)$ & $(9.3692)$ \\
\hline$N$ & 7095 & 10262 & 7095 & 10262 & 3270 & 2526 & 1237 & 1586 \\
\hline$r 2 \_a$ & 0.4489 & 0.4475 & 0.4513 & 0.4512 & 0.4674 & 0.4957 & 0.4473 & 0.4464 \\
\hline$F$ & 276.1123 & 260.6973 & 254.6637 & 249.1599 & 137.5930 & 78.5523 & 48.6276 & 40.9344 \\
\hline$P 1$ & \multicolumn{2}{|c|}{0.0818} & \multicolumn{2}{|c|}{-} & \multicolumn{2}{|c|}{0.0426} & \multicolumn{2}{|c|}{0.0208} \\
\hline$P 2$ & \multicolumn{2}{|c|}{-} & \multicolumn{2}{|c|}{0.1263} & \multicolumn{2}{|c|}{-} & \multicolumn{2}{|c|}{-} \\
\hline$P 3$ & \multicolumn{2}{|c|}{-} & \multicolumn{2}{|c|}{0.0930} & \multicolumn{2}{|c|}{-} & \multicolumn{2}{|c|}{-} \\
\hline$P 4$ & \multicolumn{4}{|c|}{0.6357} & & & & \\
\hline
\end{tabular}

Note: $(1)^{*}, * *$, and ${ }^{* * *}$ represent the significance levels of $10 \%, 5 \%$, and $1 \%$, respectively. (2) The values in parentheses are the $t$-statistics after the heteroscedasticity was corrected. (3) We apply suest to test the difference between the coefficients of the group. Among them, the empirical values P1, P2, P3, and P4 were used to test the difference between $B H C, D E I, B A C$, and SEA coefficients between groups. 


\subsection{Analysis of the Influencing Factors of Ambidextrous Innovation}

Board Human Capital and Ambidextrous Innovation: Comparison by Industry. First of all, we compared the difference between board human capital and exploitative innovation by industry. The regression results in columns (1) and (2) of Table 9 show that the estimation coefficient of board human capital was significantly positive in the high-tech industry $(t=6.0162, p<0.01)$, but not significant in the non-high-tech industry $(t=0.7488, p>0.1)$. The difference test of inter-group coefficients was consistent with the significant results, where there was a significant industry difference in the promotion effect of board human capital on exploitative innovation (the empirical value P1 corresponding to columns (1) and (2) in Table 9 was less than 0.1), and it had a greater effect in the high-tech industry. Further, the regression results in columns (3) and (4) of Table 9 show that in the high-tech industry, the estimated coefficients of a board's professional background (BAC) were not significant $(t=1.3517, p>0.1)$, but the estimated coefficients of a board's education level (DEI) and overseas experience (SEA) were significantly positive $(t=5.6824, p<0.01 ; t=2.1138, p<0.05)$. Meanwhile, in the non-high-tech industry, the above estimated coefficients were not significant. In order to prevent estimation errors, we further tested whether there were differences in coefficient between groups, and the results show that there were significant industry differences in the promotion effect of a board's education level on exploitative innovation (the empirical value P2 corresponding to columns (3) and (4) in Table 9 was less than 0.1), and the effect was more significant in the high-tech industry. There was no industry difference in a board's professional background and overseas experience (the empirical values $\mathrm{P} 3$ and $\mathrm{P} 4$ corresponding to columns (3) and (4) in Table 9 were greater than 0.1). Among them, the estimation coefficient of a board's professional background was not significant between groups, which means that the number of directors with an "output function" background on the board of directors did not affect the level and ability of the exploitative innovation of enterprises.

Then, we compared the differences between board human capital and exploratory innovation in different industries, and the regression results in columns (5) and (6) of Table 9 show that, consistent with the regression results of the whole sample, the estimated coefficient of board human capital was significantly positive in both high-tech and non-high-tech industries $(t=2.1835, p<0.05 ; t=3.8540$, $p<0.01$ ). We further tested whether there were differences in the coefficient between groups, and the results show that board human capital had no significant industrial difference in promoting exploratory innovation (the empirical value P1 corresponding to columns (5) and (6) in Table 9 was greater than 0.1 ), indicating the importance of board human capital in promoting exploratory innovation in various industries.

Further, the regression results in columns (7) and (8) of Table 9 show that in non-high-tech industries, the estimated coefficient of a board's education level (DEI) was not significant $(t=-0.9498$, $p>0.1$, and the estimated coefficient of a board's professional background $(B A C)$ and overseas experience (SEA) were both significantly positive $(t=5.3332, p<0.01 ; t=2.4582, p<0.05)$; meanwhile, the estimated coefficient was not significant in high-tech industries. In order to prevent estimation errors, we further tested whether there were differences in the coefficient between groups. The results show that there were no significant industry differences in the promotion effect of a board's education level, professional background, and overseas experience on exploratory innovation (empirical values P2-P4 corresponding to columns (7) and (8) in Table 9 were all greater than 0.1), which was consistent with the results of a full sample regression.

Board Human Capital and Ambidextrous Innovation: Comparison by Market Strength. The degree of market competition was measured using the Herfindahl index $(H H I)$ of operating income, which is calculated using the formula: $H H I=\sum X_{i}^{2}$, where $i$ represents the industry, $X_{i}$ represents the proportion of market competitors in the industry of $i$ in the total market share, which is measured using the proportion of each enterprise in the total annual sales of industry $i$. 
Table 9. Board human capital and ambidextrous innovation: comparison by industry.

\begin{tabular}{|c|c|c|c|c|c|c|c|c|}
\hline & \multicolumn{4}{|c|}{ Exploitative Innovation } & \multicolumn{4}{|c|}{ Exploratory Innovation } \\
\hline & High-Tech & Non-High-Tech & High-Tech & Non-High-Tech & High-Tech & Non-High-Tech & High-Tech & Non-High-Tech \\
\hline & (1) & (2) & (3) & (4) & (5) & (6) & (7) & (8) \\
\hline \multirow{2}{*}{ BHC } & $0.0488^{* * *}$ & 0.0037 & & & $0.0561 * *$ & $0.0602 * * *$ & & \\
\hline & $(6.0162)$ & $(0.7488)$ & & & $(2.1835)$ & $(3.8540)$ & & \\
\hline$D E I$ & & & $(5.6824)$ & $(0.0584)$ & & & $(0.0733)$ & $(-0.9498)$ \\
\hline \multirow{2}{*}{$B A C$} & & & 0.1122 & -0.0391 & & & 0.4272 & $0.9535^{* * *}$ \\
\hline & & & $(1.3517)$ & $(-0.6882)$ & & & $(1.5407)$ & $(5.3332)$ \\
\hline$S E A$ & & & $0.2880^{* *}$ & 0.1105 & & & 0.7002 & $0.6125^{* *}$ \\
\hline \multirow{2}{*}{ DOUL } & $0.0587^{*}$ & 0.0200 & $0.0597^{*}$ & 0.0203 & 0.1067 & -0.0302 & 0.1154 & -0.0328 \\
\hline & $(1.7202)$ & $(0.8059)$ & $(1.7523)$ & $(0.8250)$ & $(0.7690)$ & $(-0.3792)$ & $(0.8305)$ & $(-0.4068)$ \\
\hline \multirow{2}{*}{$S E C$} & $-0.9668^{* * *}$ & $-0.3766^{* * *}$ & $-0.9515^{* * *}$ & $-0.3844^{* * *}$ & $0.8895^{*}$ & $-1.1913^{* * *}$ & $0.9094^{*}$ & $-1.1819^{* * *}$ \\
\hline & $(-6.5658)$ & $(-5.3498)$ & $(-6.4862)$ & $(-5.3596)$ & $(1.7082)$ & $(-5.4530)$ & $(1.7451)$ & $(-5.4731)$ \\
\hline \multirow{2}{*}{$L E V$} & 0.0315 & -0.0152 & 0.0119 & -0.0128 & $-1.3002 * * *$ & $-1.0036^{* * *}$ & $-1.2503^{* * *}$ & $-1.0199^{* * *}$ \\
\hline & $(0.3479)$ & $(-0.1868)$ & $(0.1310)$ & $(-0.1579)$ & $(-3.8993)$ & $(-6.0451)$ & $(-3.6844)$ & $(-6.2126)$ \\
\hline \multirow{2}{*}{$A G E$} & -0.0594 & -0.0408 & -0.0640 & -0.0472 & $-0.5348^{* * *}$ & $-0.3876^{* * *}$ & $-0.5181^{* * *}$ & $-0.3510^{* * *}$ \\
\hline & $(-1.1558)$ & $(-1.1766)$ & $(-1.2546)$ & $(-1.2962)$ & $(-2.8675)$ & $(-4.4922)$ & $(-2.7502)$ & $(-4.1371)$ \\
\hline _cons & $(-0.8444)$ & (1.8468) & $(-1.9911)$ & (1.9039) & (2.3974) & (3.9986) & $(2.2481)$ & (3.6125) \\
\hline$N$ & 3270 & 2526 & 3270 & 2526 & 1237 & 1586 & 1237 & 1586 \\
\hline$r 2 \_a$ & 0.1739 & 0.0363 & 0.1762 & 0.0362 & 0.1739 & 0.2164 & 0.1731 & 0.2281 \\
\hline$F$ & 20.9973 & 3.9760 & 31.3923 & 3.7924 & 13.3909 & 14.6756 & 12.2501 & 14.7746 \\
\hline P1 & \multicolumn{2}{|c|}{0.0000} & \multicolumn{2}{|r|}{-} & \multicolumn{2}{|c|}{0.8900} & \multicolumn{2}{|r|}{-} \\
\hline$P 2$ & \multicolumn{2}{|r|}{-} & \multicolumn{2}{|c|}{0.0000} & \multicolumn{2}{|r|}{-} & \multicolumn{2}{|c|}{0.6008} \\
\hline P3 & \multicolumn{2}{|r|}{-} & \multicolumn{2}{|c|}{0.1308} & & - & \multicolumn{2}{|c|}{0.1071} \\
\hline P4 & & & \multicolumn{2}{|c|}{0.2821} & & & \multicolumn{2}{|c|}{0.8813} \\
\hline
\end{tabular}

Note: $(1)^{*}, * *$, and ${ }^{* * *}$ represent the significance levels of $10 \%, 5 \%$, and $1 \%$, respectively. (2) The values in parentheses are the t-statistics after the heteroscedasticity was corrected. (3) We apply suest to test the difference between the coefficients of the group. Among them, the empirical values P1, P2, P3, and P4 were used to test the difference between $B H C, D E I, B A C$, and $S E A$ coefficients between groups.

We compared the difference between board human capital and exploitative innovation according to the strength of market competition. The regression results in columns (1) and (2) of Table 10 show that, consistent with the results of a full sample regression, the estimated coefficient of board human capital was significantly positive no matter whether the market competitiveness was strong or weak $(t=2.5299, p<0.05 ; t=4.8353, p<0.01)$. The results show that the promotion effect of board human capital on exploitative innovation was not affected by market competition (the empirical value P1 corresponding to columns (1) and (2) in Table 10 was greater than 0.1). Therefore, no matter how competitive the market is, enterprises should attach importance to the value of board human capital in improving exploitative innovation. Further, the regression results in columns (3) and (4) of Table 10 show that, consistent with the results of the whole sample regression, for enterprises in different market competition environments, there was a significantly positive correlation between a board's 
education level and exploitative innovation $(t=2.0260, p<0.05 ; t=3.6458, p<0.01)$, and there was no significant difference in either coefficient or correlation, indicating the importance of a board's education level for exploitative innovation. Consistent with the results of the full sample regression, a board's professional background was not affected by the strength of market competitiveness and had no significant correlation with exploitative innovation. When the market competition was weak, the estimated coefficient of a board's overseas experience was significantly positive $(t=2.0524, p<0.05)$. On the contrary, when the market competition was strong, the estimated coefficient was not significant. Further the inter-group coefficient difference test results show that there was no significant difference in the grouping regression (the empirical value P4 corresponding to columns (3) and (4) in Table 10 was greater than 0.1). It can be seen that improving a board's overseas experience had a positive significance for promoting the exploitative innovation of enterprises.

The regression results in columns (5) and (6) of Table 10 show that when the market competition was weak, the estimated coefficient of board human capital was significantly positive $(t=5.4551$, $p<0.01)$. On the contrary, when the market competitiveness was strong, the estimated coefficient was not significant $(t=0.1006, p>0.1)$. The inter-group coefficient test further verified the above results (the empirical value P1 corresponding to columns (5) and (6) in Table 10 was less than 0.1). When the market competition was weak, board human capital played a stronger role in promoting exploratory innovation. The reason for this may have been that for enterprises to achieve a technological breakthrough, they often need to have certain oligopolistic market power to guarantee all the resources for research and development. If the market competition is weaker, the market concentration would be higher. In industries with high market concentration, there are often oligopolies or monopolies, and the market power of these large enterprises can ensure that they have enough $R \& D$ investment. In this case, board human capital is more likely to play a role in creating an advantage in raising resources for exploratory innovation.

Further, the regression results in columns (7) and (8) of Table 10 are observed: when the market competition was strong, the estimated coefficient of a board's education level was significantly negative $(t=-2.0224, p<0.05)$. In contrast, when the market competitiveness was weak, the estimated coefficient was not significant $(t=1.0190, p>0.1)$. Furthermore, the inter-group coefficient difference test shows that there were significant differences in the relationship between a board's education level and exploratory innovation in different market competition environments (the empirical value P2 corresponding to columns (7) and (8) in Table 10 was smaller than 0.1). It can be seen that the influence of a board's education level on exploratory innovation was greatly influenced by the strength or weakness of industry competition, and the two influence directions were different, which may be the reason why the results in the full sample regression were not significant. Consistent with the results of a full sample regression, the estimated coefficient of a board's professional background $(B A C)$ was significantly positive, regardless of the strength of market competition $(t=2.4699, p<0.05$; $t=3.2090, p<0.01$ ). In order to prevent estimation errors, we further tested the coefficient differences between groups and the results show that there was no significant difference (the empirical value P3 corresponding to columns (7) and (8) in Table 10 was greater than 0.1 ), where the promotion effect of a board's professional background was not affected by the market competition. When the market competition was weak, the estimated coefficient of a board's overseas experience was significantly positive $(t=3.8818, p<0.01)$, but when the market competition was strong, the estimated coefficient was not significant. The inter-group coefficient difference test further confirmed the above conclusion (the empirical value P1 corresponding to columns (5) and (6) in Table 10 was less than 0.1). When the market competitiveness was weak, the promotion effect was more significant, indicating that in large enterprises with a high market concentration, it was easier to develop the promotion effect of a board's overseas experience on the exploratory innovation of enterprises. 
Table 10. Board human capital and ambidextrous innovation: comparison by market strength.

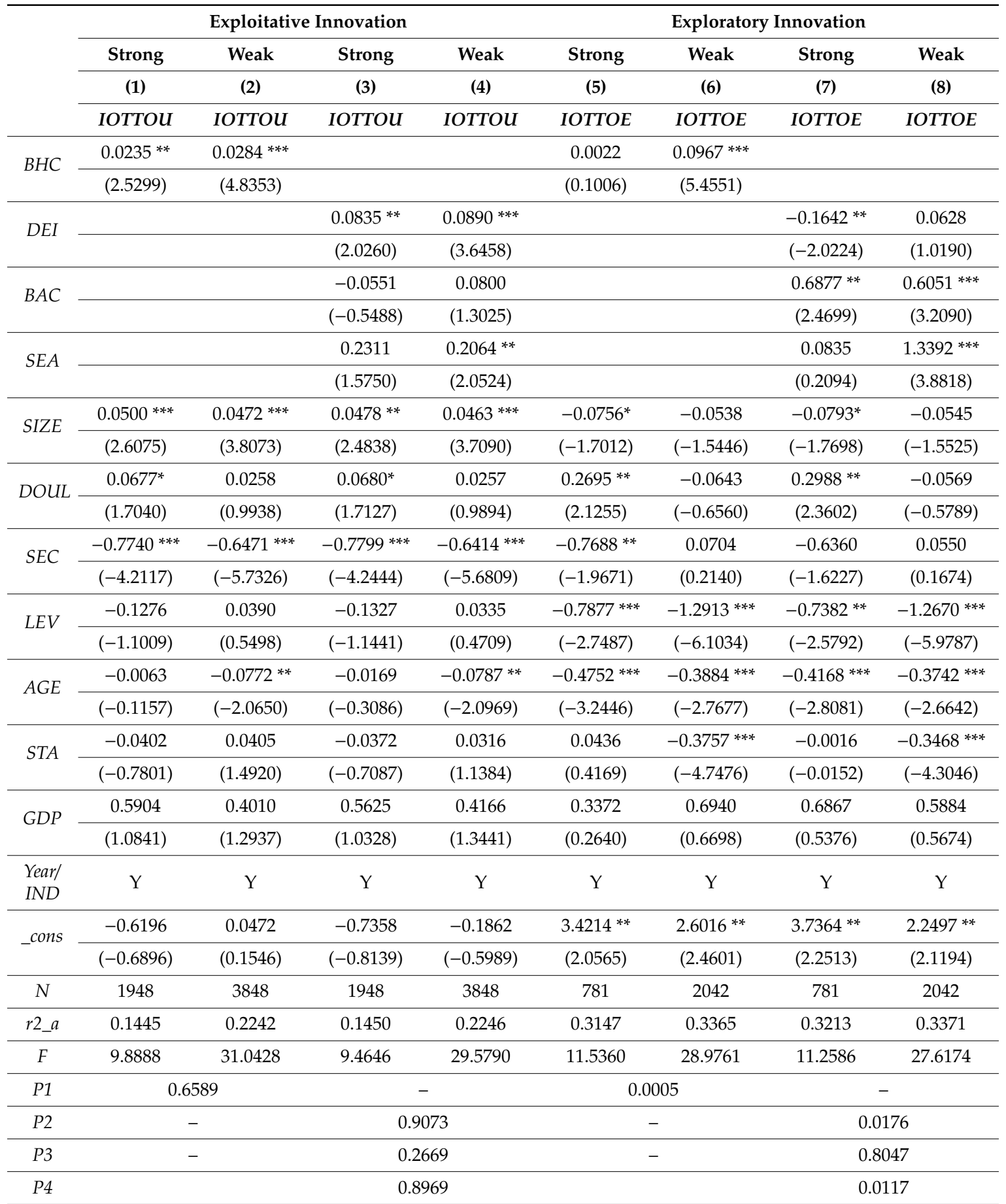

Note: $(1)^{*}, * *$, and ${ }^{* * *}$ represent the significance levels of $10 \%, 5 \%$, and $1 \%$, respectively. (2) The values in parentheses are the t-statistics after the heteroscedasticity was corrected. (3) We apply suest to test the difference between the coefficients of the group. Among them, the empirical values P1, P2, P3, and P4 were used to test the difference between $B H C, D E I, B A C$, and $S E A$ coefficients between groups.

\section{Conclusions and Discussion}

\subsection{Conclusions}

In this paper, we show clear empirical evidence that board human capital had a significantly favorable impact on enterprise growth, and ambidextrous innovation played as role as part of the intermediary role. Further analysis shows that a board's education level had a significant positive 
impact on enterprise growth, in which exploitative innovation played as role as part of the mediating effect. The research of Wincent et al. [52] shows that heterogeneity of a board's knowledge and skill is particularly important for incremental innovation, while a board's education level is particularly important for radical innovation. However, this paper finds that a board's education level had a significant role in promoting exploitative innovation, but there was no significant correlation with exploratory innovation, which may be related to the strong awareness of risk aversion of highly educated directors. Although the board of directors with a high degree of education attached more importance to the investment in enterprise research and development, the board of directors faced great pressure from inside and outside the enterprise when making decisions on enterprise innovation because radical innovation usually means a higher risk and a longer return period. Meanwhile, directors with higher education levels were usually more rational. As a result, they were part of the enterprise project engaging in high risk prevention.

Existing studies have suggested that decision-makers with R\&D, marketing, and design experience pay more attention to the technological development of enterprises and tend to increase input in product and technological innovation [53]. The proportion of directors with an "output function" background was negatively correlated with enterprise growth, which may have been related to the directors with this background lacking professional management knowledge and experience, and the strategic decision-making having a risk preference. When studying the relationship between a board's professional background and ambidextrous innovation, it was found that there was no significant correlation between a board's professional background and exploitative innovation; but there was a significantly positive correlation with exploratory innovation. A board's overseas experience was positively correlated with enterprise growth, among which ambidextrous innovation played a partly mediating role. Therefore, a board's overseas experience can significantly influence enterprise growth through exploitative innovation and exploratory innovation.

The balance effect between exploitative innovation and exploratory innovation can enhance enterprise growth to a certain extent. The balance effect between exploitative innovation and exploratory innovation can prevent the dangers of a "core rigidity" and an "innovation trap" caused by excessive emphasis on one party, which is conducive to reducing business risks, ensuring the improvement of short-term financial performance and the construction of a sustainable competitiveness of enterprises to significantly improve enterprise growth.

The difference analysis of the influencing factors of enterprise growth shows that board human capital played a more significant role in promoting enterprise growth in the high-tech industry. There were significant industry differences in the role of ambidextrous innovation in promoting enterprise growth. Among them, the promoting effect of exploitative innovation on enterprise growth was more significant in non-high-tech industries; while the promoting effect of exploratory innovation on enterprise growth was more significant in high-tech industries. This paper shows that ambidextrous innovation played an irreplaceable role in promoting enterprise growth. Due to the low level of innovation in various industries at present, the development of ambidextrous innovation was extremely unbalanced. In particular, non-high-tech industries relied too much on exploitative innovation and exploratory innovation had not been developed into an important driving force to promote enterprise growth.

The difference analysis of the influence factors of ambidextrous innovation shows that board human capital had a significant industrial difference in the promotion of exploitative innovation, which was stronger in the high-tech industry; meanwhile, there was no significant industrial difference in the promotion of exploratory innovation. Arrow [54] believes that a competitive market is more likely to stimulate enterprise innovation, while this study finds that board human capital played an important role in promoting exploitative innovation, which was not affected by the degree of market competition. The research on exploratory innovation supports Schumpeter's hypothesis that there is a positive correlation between technological innovation and market concentration. It shows that in the environment of high market concentration and weak market competition, some enterprises often have 
certain market dominance, which ensures that enterprises have sufficient investment in innovation and $R \& D$, and board human capital is more likely to play a role as an exploratory innovation advantage resource for enterprises. Moreover, although listed enterprises in China have the same level of board human capital, their promotion of ambidextrous innovation will be significantly different due to the influence of industry differences and market competition.

\subsection{Contribution}

This paper contributes to relevant research in a couple of ways. First, we introduce ambidextrous innovation as a mediator from the perspective of "enterprise resources-enterprise capability-enterprise growth," explain the impact of board human capital on enterprise growth from internal and external factors and reveal the favorable role of board human capital in the process of enterprise growth. Second, the leading antecedent variable was an important research direction of the antecedent variable of ambidextrous innovation organization. The existing research mainly focuses on the "leadership duality" characteristics at the individual level, while the research on the "top management team duality" characteristics at the organizational level is in the initial stage. We enrich the related research on characteristics regarding "top management team duality" by exploring the impact of board human capital on ambidextrous innovation. Third, based on the research of the endogenous perspective of enterprise growth, we focused on the impact of environmental factors at the industry level. By grouping enterprises according to the nature of the industry and the intensity of market competition, we revealed the differences in the influence of board human capital on ambidextrous innovation and enterprise growth. There was a guiding significance for enterprises in different industries to build a sustainable competitive advantage.

\subsection{Practical Implications}

At present, emerging production factors, such as technology and knowledge, should gradually become the main driving force for enterprise growth [42]. In order to improve the level and quality of enterprise innovation and promote the healthy and sustainable development of enterprises, it is necessary to establish the coordination mechanism between the government and enterprises. Based on the research conclusions, the following countermeasures are proposed.

First, listed companies should fully recognize the favorable role of board human capital. By optimizing the composition of the board of directors and improving the level of board human capital, enterprises can build a sustainable competitive advantage. Directors with a higher educational level, professional management knowledge, and overseas background can significantly improve enterprise growth, which should be taken as an important basis for the selection and recruitment of directors. Furthermore, the human capital level of existing directors can be constantly optimized through self-development and management development. Enterprises can also choose to set up practical training classes for senior managers, along with other ways, to help directors achieve a breakthrough in ideas and improve their management ability. In addition, enterprises should build cooperation platforms with overseas universities and research institutes, and constantly introduce advanced management knowledge and experience. Directors without overseas background in an enterprise can continuously expand their international vision and management experience through overseas study or dispatch.

Second, the relative balance between exploitative innovation and exploratory innovation should be highly valued in the process of enterprise development. Since the reform and opening up policy was implemented, China has gradually established a modern technology system and narrowed the gap with the world's advanced technology by means of "introduction, digestion, absorption and re-innovation." China has made great progress in the exploitative innovation level, and promoted the rapid and efficient development of its economy. However, as China's economy enters a higher stage of development, the existing knowledge and technical level can no longer meet the needs of economic development due to various contradictions. Enterprises will rely on original innovation if they want to 
compete in the international market. In order to become a supporting force for enterprise growth in non-high-tech industries, the development and cultivation of exploratory innovation ability should have great importance attached to it.

Third, listed companies should formulate innovative strategies in line with the current stage of development, according to the nature of the industry and the market competition environment. Different industries have different demands and focus on innovation, so different innovation strategies are formed based on different considerations, such as organizational culture [55]. At present, the high-tech industry focuses on exploratory innovation; meanwhile, the non-high-tech industry prefers exploitative innovation. Therefore, in the process of enterprise innovation, on the one hand, enterprises should be committed to the pursuit of ambidextrous innovation and enterprises should pay attention to the balanced development of exploitative innovation and exploratory innovation in the process of development, rather than relying too much on a certain type of innovation. On the other hand, enterprises should pursue substantial innovation and constantly improve the level and quality of innovation to avoid the waste of innovation resources. In addition, enterprises should have a correct understanding of the significance of industry competition to enhance their sustainable competitive advantage as a source of power.

\subsection{Limitations and Future Research}

There are still some imperfections in this study. We only selected board's education level, professional background, and overseas experience to measure board human capital. Although these dimensions have important considerations in enterprise recruitment and career promotion, they are not sufficient to comprehensively capture board human capital, which needs to be further supplemented in subsequent studies. We do not consider the important role played by board social capital in promoting enterprise growth. The existing research suggests that board human capital and board social capital are interdependent and inseparable, which together constitute board capital [56]. Therefore, the relationship between board social capital and enterprise growth and ambidextrous innovation should be considered in the future research.

Author Contributions: Z.L. designed this study, provided the resources, and revised and finalized the manuscript; G.-D.C. collected and analyzed the data and wrote the original paper; and L.H. provided the methodology and revised the paper.

Funding: This work was supported by the China State Scholarship Fund (File No.201705215032).

Acknowledgments: The authors would like to express their appreciation to the anonymous reviewers for their valuable comments.

Conflicts of Interest: The authors declare no conflict of interest.

\section{References}

1. Hui, E.C. Analysis on the growth of listed companies. Res. Financ. Econ. Iss. 1998, 4, 50-52.

2. Pettus, M.L. The Resource-Based View as a Developmental Growth Process: Evidence from the Deregulated Trucking Industry. Acad. Manag. J. 2001, 44, 878-896.

3. Wu, A.Q.; Jia, S.H. A review on the mechanism of firm growth. Sci. Res. Manag. 2007, 2, 53-58.

4. Balkin, D.B.; Markman, G.D.; Gomez-Mejia, L.R. Is CEO Pay in High-Technology Firms Related to Innovation? Acad. Manag. J. 2000, 43, 1118-1129. [CrossRef]

5. Pfeffer, J. Size and Composition of Corporate Boards of Directors: The Organization and its Environment. Admin. Sci. Quart. 1972, 17, 218-228. [CrossRef]

6. Zhou, J.; Jin, Y.Y.; Liu, X.Y. Summary of Board Capital Research. Fore. Econ. Manag. 2010, 32, 27-35.

7. Kor, Y.Y.; Sundaramurthy, C. Experience-Based Human Capital and Social Capital of Outside Directors. J. Manag. 2009, 35, 981-1006. [CrossRef]

8. Zhang, W.J.; Li, K.; Wang, S.M. A Research of the Regulating Role of CEO Power over the Internal Mechanism of Board of Director's Influence on Corporate Innovation. Bus. Rev. 2018, 30, 70-82. 
9. Zhou, J.; Ren, S.H.; Jin, Y.Y.; Li, X.Y. The Impact of Board Capital on R\&D Spending-Empirical Evidence from the Listed High-tech Companies in China. Res. Dev. Manag. 2012, 24, 67-77.

10. Stephen, K.N.; Waswa, B.; Venancio, T.; Joseph, M.N. Board role performance in service organizations: The importance of human capital in the context of a developing country. Soc. Responsib. J. 2014, 10, 646-673.

11. Välikangas, L.; Gibbert, M. Boundary-setting strategies for escaping innovation traps. Mit. Sloan. Manag. Rev. 2005, 46, 58-65. [CrossRef]

12. Wang, X.F.; Lv, W.D.; Wang, Q.Y. The Research of the Integration Pattern of Exploration Innovation and Exploitation Innovation on the Basis of Structural Ambidexterity. Sci. Technol. Manag. Res. 2017, 37, 19-24.

13. Lin, J.; Gao, X.; Zhang, M. Knowledge-based Enterprises Innovation Performance by Exploitative and Exploratory Ambidexterity Driving. Soft Sci. 2016, 30, 59-63.

14. Certo, S.T. Influencing Initial Public Offering Investors with Prestige: Signaling with Board Structures. Acad. Manag. Rev. 2003, 28, 432-446. [CrossRef]

15. Drees, J.M.; Heugens, P.P.M.A.R. Synthesizing and Extending Resource Dependence Theory: A Meta-Analysis. J. Manag. 2012, 39, 1666-1698. [CrossRef]

16. Liu, B.; Guo, S.Y. An Empirical Research on the Relationship between the Human Capital and Heterogeneity of the Board and Firm Performance. J. Manag. Sci. 2017, 30, 23-34. Available online: https://doi.org/10.3969/j. issn.1672-0334.2017.03.003 (accessed on 22 July 2019).

17. Liu, F.C.; Mo, J.X.; Ma, R.K. The Impact of TMT Overseas Background on Firm Innovation Performance. Bus. Rev. 2017, 29, 135-147.

18. Song, J.B.; Wen, W. Can Directors' Foreign Experience Promote Corporate Innovation? China Soft Sci. 2016, 11, 109-120.

19. Dai, Y.; Kong, D.; Liu, S. Returnee Talent and Corporate Investment: Evidence from China. Eur. Acc. Rev. 2018, 27, 313-337. [CrossRef]

20. Chen, H.L.; Chang, C.Y.; Hsu, W.T. Does Board Co-Working Experience Influence Directors' Decisions Towards Internationalization? Manag. Int. Rev. 2017, 57, 65-92. [CrossRef]

21. Oxelheim, L.; Gregorič, A.; Randøy, T.; Thomsen, S. On the internationalization of corporate boards: The case of Nordic firms. J. Int. Bus. Stud. 2013, 44, 173-194. [CrossRef]

22. March, J.G. Exploration and exploitation in organizational learning. Organ. Sci. 1991, 2, 71-87. [CrossRef]

23. Daellenbach, U.; Mccarthy, A.M.; Schoenecker, T.S. Commitment to Innovation: The Impact of Top Management Team Characteristics. R D Manag. 2002, 29, 199-208. [CrossRef]

24. Westphal, C.J.D. The Strategic Context of External Network Ties: Examining the Impact of Director Appointments on Board Involvement in Strategic Decision Making. Acad. Manag. J. 2001, 44, 639-660.

25. Xi, L.; Peng, C.; Li, D.Y. The Effect of Intellectual Capital on the Synergy of Dual Innovation: The Adjustment of the Behavior Integration of the Senior Management Team. Sci. Technol. Prog. Policy 2016, 33, 142-148.

26. Gradstein, M.; Justman, M. Education, Social Cohesion, and Economic Growth. Am. Econ. Rev. 2002, 92, 1192-1204. [CrossRef]

27. Bantel, K.A.; Jackson, S.E. Top management and innovations in banking: Does the composition of the top team make a difference? Strateg. Manag. J. 1989, 10, 18. [CrossRef]

28. Hambrick, D.C.; Mason, P.A. Upper Echelons: The Organization as a Reflection of Its Top Managers. Acad. Manag. Rev. 1984, 9, 193-206. [CrossRef]

29. Chen, L.Y.; Lai, J.H. The effect of board human capital on the performance of technical alliance investments. R D Manag. 2017, 47, 265-276. [CrossRef]

30. Vandenbroucke, E.; Knockaert, M.; Ucbasaran, D. Outside Board Human Capital and Early Stage High-Tech Firm Performance. Entrep. Theory Pract. 2014, 40, 759-779. [CrossRef]

31. Luo, S.Y.; Yu, Y.D. The technology transfer and intellectuals returning to China: A case study based on China's photovoltaic industry. Manag. World 2012, 11, 124-132.

32. Huang, T.; Ge, Y.Y. Impact of overseas experience of top management team on enterprises' innovation performance: The empirical study of information technology listed companies. Sci.-Technol. Manag. 2018, 20, 80-86.

33. Benner, M.J.; Tushman, M.L. Exploitation, Exploration, and Process Management: The Productivity Dilemma Revisited. Acad. Manag. Rev. 2003, 28, 238-256. [CrossRef]

34. Atuahene-Gima, K.; Murray, J.Y. Exploratory and Exploitative Learning in New Product Development: A Social Capital Perspective on New Technology Ventures in China. J. Int. Mark. 2007, 15, 1-29. [CrossRef] 
35. Jiao, H. The Road to Establishing the Competitive Advantage of the Dual Type of Organizations: Founded on the Case Study Theory of the Dynamic Capabilities. Manag. World 2011, 11, 76-91.

36. Su, X.; Zhou, S.S. Ambidextrous Innovation and Firm Competitive Position: Empirical Evidence from Listed Companies in China. South. Chin. J. Econ. 2019, 5, 52-77.

37. Wu, Y.; Liang, Q.Z.; Wei, Z.L. An Empirical Study on the Effect of Ambidextrous Technological Innovation and Market Orientation on Firm Performance: Disruptive Innovation View. Sci. Sci. Manag. S. T. 2013, 34, 140-151.

38. Cao, Q.; Gedajlovic, E.; Zhang, H. Unpacking Organizational Ambidexterity: Dimensions, Contingencies, and Synergistic Effects. Organ. Sci. 2009, 20, 781-796. [CrossRef]

39. Raisch, S.; Birkinshaw, J.; Probst, G.; Tushman, M.L. Organizational Ambidexterity: Balancing Exploitation and Exploration for Sustained Performance. Organ. Sci. 2009, 20, 685-695. [CrossRef]

40. Guo, T.; Xing, L.; Huang, Y. Study on the Influence of Knowledge Transfer of Innovation Network on Firm's Innovation Performance: The Intermediary Role of Ambidextrous Innovation. Sci. Technol. Prog. Policy 2017, 34, 114-119.

41. Teece, D.J. Explicating Dynamic Capabilities: The Nature and Microfoundations of (Sustainable) Enterprise Performance. Strateg. Manag. J. 2007, 28, 1319-1350. [CrossRef]

42. Wang, J.; Luo, F.K. Technology and Knowledge Investment, the Allocation of Element Capital and Enterprise Growth. Nankai Bus. Rev. 2017, 20, 90-99.

43. Fang, F.; Cai, W.X. Banking Competition and Firms' Growth: Empirical Evidence from Industrial Enterprises Database. Manag. World 2016, 7, 63-75.

44. Xu, W.B.; Zhou, J. The Mechanisms of Board Capital Affecting Enterprises' Investment Efficiency: Supervision Effects or Resources Effects? Econ. Manag. J. 2017, 39, 69-84.

45. Wang, N.; He, J.; Huang, J. The Effect of Board of Directors Capital and CEO Power on R\&D Investment: An Analysis of Data from GEM Listed Corporation. Commer. Res. 2017, 1, 108-117.

46. Bi, X.F. Government Subsidies, Financial Slack and Ambidextrous Innovation. Account. Res. 2017, 1, 46-52, 95. [CrossRef]

47. Maznevski, M.L. Understanding Our Differences: Performance in Decision-Making Groups with Diverse Members. Hum. Relat. 1994, 47, 531-552. [CrossRef]

48. Wen, Z.L.; Ye, B.J. Analyses of Mediating Effects: The Development of Methods and Models. Adv. Psychol. Sci. 2014, 22, 731-745. [CrossRef]

49. Lu, T.; Dang, Y. Corporate Governance and Innovation: Differences among Industry Categories. Econ. Res. J. 2014, 49, 115-128.

50. Nie, H.H.; Tan, S.T.; Wang, Y.F. Innovation, Firm Size and Market Competition: Panel Data Analysis Based on Chinese Enterprise Level. Word Econ. Stud. 2008, 7, 57-66.

51. Wang, C.P.; Miao, T. Board Capital, Product Market Competition and Corporate R\&D Investment. China Soft Sci. 2018, 8, 116-124.

52. Wincent, J.; Anokhin, S.; Örtqvist, D. Does network board capital matter? A study of innovative performance in strategic SME networks. J. Bus. Res. 2010, 63, 265-275. [CrossRef]

53. Finkelstein, S. Power in top management teams: Dimensions, measurement, and validation. Acad. Manag. J. 1992, 35, 505-538.

54. Arrow, K.J. Economics Welfare and the Allocation of Resources for Invention. In The Rate and Direction on Incentive Activity: Economic and Social Factors, National Bureau of Economic Research; Princeton University Press: Princeton, NJ, USA, 1962.

55. Chen, Z.; Huang, S.L.; Liu, C.; Min, M.; Zhou, L.Y. Fit between Organizational Culture and Innovation Strategy: Implications for Innovation Performance. Sustainability 2018, 10, 3378. [CrossRef]

56. Hillman, A.J.; Dalziel, T. Boards of Directors and Firm Performance: Integrating Agency and Resource Dependence Perspectives. Acad. Manag. Rev. 2003, 28, 383-396. [CrossRef]

(C) 2019 by the authors. Licensee MDPI, Basel, Switzerland. This article is an open access article distributed under the terms and conditions of the Creative Commons Attribution (CC BY) license (http://creativecommons.org/licenses/by/4.0/). 